\title{
Asset Allocation and Security Selection in Theory \& in Practice: A Literature Survey from a Practitioner's Perspective
}

\author{
Hany Fahmy ${ }^{1}$ \\ ${ }^{1}$ Faculty of Mathematics, University of Waterloo, ON, Canada. \\ ${ }^{1}$ Correspondence: hfahmy@uwaterloo.ca; hfahmy@hf-consulting.ca
}

Received: January 16, 2015

Accepted: January 31, 2015

Available online: March 17, 2015

doi:10.11114/afa.v1i2.725

URL: http://dx.doi.org/10.11114/afa.v1i2.725

\begin{abstract}
Whether for the sake of trying to make a fortune or for the sake of knowledge, both practitioners and academicians have had interests in studying the behavior of financial time series data since the existence of financial markets. Academicians contributed equilibrium models that aim to describe the process of price formation in capital markets. Over time, two schools of thoughts were established: the efficient markets school and the behavioral finance school. Proponents of the former believed in the Efficient Markets Hypothesis (EMH), whereas the latter brought evidence from behavioral finance and neurosciences showing that investors, especially retail traders, exhibit irrational behavior, which can explain the observed violations of the EMH in financial markets. Practitioners were not interested in developing models of price formation; rather they were interested in developing techniques to analyze and predict the price movements of financial assets. Same as academicians, practitioners can also be grouped into two schools of thought: the fundamental analysis school and the technical analysis school. Although both schools of thought share the same objective, which is to give advice on what and when to buy and sell assets for the sake of making profit, they differ in their ways of analysis.

The significant role played by academicians and practitioners in the finance industry and the interconnection between both schools and the approaches followed within each of them are best perceived in the way financial assets are allocated and portfolios are constructed. In an attempt to cross that bridge between the theory of price formation in financial markets and its practical implementations, this paper aims to survey the literature on both the theoretical and the practical frontiers of asset allocation and portfolio construction, and the best way of carrying on this task is through a thorough description of the portfolio management process (PMP). To this end, the paper breaks the PMP into three main steps, namely, portfolio planning, portfolio construction, and portfolio evaluation, in that order, and then discusses each step while surveying the literature pertaining to it. In addition to the description of the PMP, the paper also answers questions of particular interest to young practitioners, who are taking their first steps towards a career in the finance industry, such as: How portfolio theory, which is at the core of finance theory, is applied in practice? How a financial portfolio of assets is constructed in practice? How the individual assets forming a portfolio are selected and allocated? And is the process of constructing portfolios unique? Although the answers to these questions might appear to be simple and straightforward, they are, in fact, quite complicated. The complication lies not only in making the theory, which is based on certain restrictive and unrealistic assumptions, work in practice, but also in the simultaneous use of a variety of tools and financial concepts in forming a sound investment strategy.
\end{abstract}

Keywords: Asset Allocation, Security Selection, Portfolio Construction, Portfolio Management Process, Investment Policy Statement, Asset Valuation, Fundamental Analysis, Technical Analysis, Behavioral Finance, Efficient Markets Hypothesis, CAPM, Mean-Variance Optimization.

\section{Introduction}

Whether for the sake of trying to make a fortune or for the sake of knowledge, both practitioners and academicians have had interests in studying the behavior of financial time series data since the existence of financial markets. Not only their motives were different, but also their practices. On one hand, financial practitioners believed that financial time series could be forecasted. Driven by their financial motives, they were set to exploit profit opportunities by forecasting and predicting the behavior of financial time series in capital markets. Academicians, on the other hand, were occupied with answering the question of whether or not it is possible to forecast financial time series. Despite the fact that 
academicians and practitioners differ in their motives, they both enhanced our understanding of the price formation process in financial markets.

Academicians contributed equilibrium models that aim to describe the process of price formation in capital markets. Over time, two schools of thoughts were established: the efficient markets school and the behavioral finance school. Proponents of the former school of thought believed that resources are efficiently allocated among participants in capital markets. In an efficient setup, capital markets provide accurate signals for firms and investors that enable them to make efficient investment decisions. In other words, the proponents of this school of through entertained the Efficient Markets Hypothesis (EMH), which posits that, at any point in time, asset prices fully reflect all available information in the market. Empirical evidence, however, shows0 otherwise. The EMH does not hold all the time. Recent evidence from behavioral finance and neurosciences shows that investors (especially retail traders) exhibit irrational behavior, which can explain this violation of the EMH. This led to the formation of the latter school of thought; the behavioral finance school.

Practitioners were not interested in developing models of price formation; rather they were interested in developing techniques to analyze and predict the price movements of financial assets. Same as academicians, practitioners can also be grouped into two schools of thought: the fundamental analysis school and the technical analysis school. Although both schools of thought share the same objective, which is to give advice on what and when to buy and sell assets for the sake of making profit, they differ in their ways of analysis. The proponents of the fundamental analysis believe that any asset has a foundation value or intrinsic value. Due to market conditions, the actual price of the asset fluctuates continuously around this intrinsic value; it could fall below or rise above this value. This fluctuation implies that the actual market price of the asset will eventually reach its intrinsic value but will rarely remain at it. This, in turn, creates buying and selling opportunities when the asset is undervalued or overvalued respectively. Finding the intrinsic value of the asset under consideration is the main objective of fundamental analysts. The proponents of technical analysis, on the other hand, believe that the study of past price movements helps in predicting its future movements. The general consensus among technical analysts is that fundamentals are irrelevant because all market information are reflected in the price process, and thus, studying the past behavior of the price series is the best way to predict its future movements. Practitioners in the finance industry usually entertain the views and methods of both schools in developing their strategies. I can safely argue, with a 95\% percent confidence, that most of the financial analysis strategies use a combination of the fundamental and the technical approach.

The significant role played by academicians and practitioners in the finance industry and the interconnection between both schools and the approaches followed within each of them are best perceived in the way financial assets are allocated and portfolios are constructed. The process of asset allocation and portfolio construction is a multidimensional process for it involves the simultaneous application of fundamental and technical analysis of various asset classes, industry analysis, macroeconomic analysis, risk assessment, mean-variance optimization, arbitrage, performance evaluation, and planning. Each concept is a topic by itself that has its own theoretical foundation and practical implementation. The challenge is to make the best use of all these topics together in the form of a strategy that, hopefully, yields a higher rate of return than that offered by the market. This strategy is not unique; it varies from one practitioner to the other. A successful strategy that leads to a portfolio of assets that beats the market is the result of the developer's talent, years of experience, and knowledge. This combination is what distinguishes one successful financial planner or portfolio manager from another in the finance industry.

In an attempt to cross that bridge between the theory of price formation in financial markets and its practical implementations, this paper aims to survey the literature on both the theoretical and practical frontiers of asset allocation and security selection, and the best way of carrying on this task is through a thorough description of a process that has both concepts at its core; the portfolio management process, or PMP for short. To this end, the paper breaks the PMP into three main steps as shown in Figure 1; namely, portfolio planning, portfolio construction, and portfolio evaluation, in that order, and then discusses each step while surveying the literature pertaining to it. It is worth mentioning that the PMP should not be viewed as a one-off service, but rather a continuous process. Hence, the feedback from the evaluation steps to the planning step. In addition to the description of the PMP, the paper also answers questions of particular interest to young practitioners, who are taking their first steps towards a career in the finance industry, such as: How portfolio theory, which is at the core of finance theory, is applied in practice? How a financial portfolio of assets is constructed in practice? How the individual assets forming a portfolio are selected and allocated? And is the process of constructing portfolios unique? Although the answers to these questions might appear to be simple and straightforward, they are, in fact, quite complicated. The complication lies not only in making the theory, which is based on certain restrictive and unrealistic assumptions, work in practice, but also in the simultaneous use of a variety of tools and financial concepts in forming a sound investment strategy.

In terms of organization, the paper is organized as follows: Section 1 is an introduction. It sets the stage to the portfolio 
management process. Section 2 discusses the portfolio planning phase, which is the first stage in portfolio construction. Section 3 discusses the two main pillars of portfolio construction: asset allocation and security selection. The theoretical foundation and the practical applications of both concepts are discussed and analyzed thoroughly in this section. Finally, Section 4 is devoted to discuss the last stage of the PMP, which is portfolio evaluation. Finally, Section 5 concludes.

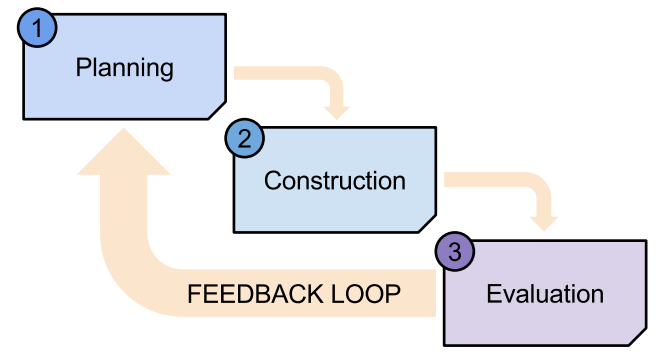

Figure 1. The Portfolio Management Process.

Before we begin the discussion on the first step of the PMP, a few words regarding investment management are in order. Once an entity, i.e., an individual investor or an institution, has made the decision to invest, it chooses one of two options; either to invest by itself for itself or to hire professional money manager(s) to invest on its behalf. The former strategy is known as proprietary investing whereas the latter is investment management.

In a proprietary investment setting, all gains or losses resulting from proprietary investment remain with the entity itself. Although it is more convenient and effective, this type of investment faces a number of challenges such as the costs of developing and maintaining proprietary investment capabilities, which must be taken into account when calculating the net gains or losses from investing. Moreover, proprietary investment activities come with significant potential for conflict of interest with the entity's core business, so precautions must be taken to avoid negative impact of such issues. Proprietary trading is a notorious example of proprietary investing that is practiced by many financial institutions in order to generate additional profits via very short-term buying and selling of securities. This practice has received much criticism from the financial regulators for its alleged role in the recent financial crisis. (Note 1)

Alternatively to proprietary investment, an entity can decide to hire a third-party investment management company. In such arrangement, the entity providing the money for investment is the client or the investor, and the investment management company is the service provider. To help manage client's money, investment management companies can provide a comprehensive set of services ranging from simple investment advice to full-service investment management and reporting. Gross gains or losses from investment remain with the client. However, net gains or losses are reduced by the compensation paid to the investment manager and the other service providers (if any).

Investment managers are compensated for their work by their clients via an investment management fee, which is usually calculated as a fixed percentage of assets under management. In addition to management fees, there are often also performance fees for managers who outperform their benchmarks. Because investors with different degrees of risk-aversion are putting their money under the control of investment managers, the fiduciary duty that the investment managers have towards their clients is crucial. This is true because potential conflict of interest, which is similar in essence to the principal-agent problem, might arise between the owners of the investment company and their financial advisers or managers and, hence, the impact of the compensation arrangements on the conflict of interest between these two groups is an issue worth studying. In particular, in the case of US mutual funds, the impact that compensation contracts have on portfolio management investment decisions is significantly important. As documented in Starks (1987) and Golec and Starks (2004), prior to 1971, in addition to the investment fee as a percentage of assets under management, mutual funds in the US used two forms of performance incentive fee schedules; a symmetric performance fee schedule and (2) an asymmetric one. Under the former schedule, in case of good performance, the fund manager received a percentage of assets under management plus a bonus measured as a percentage of the gain in fund or portfolio value relative to some benchmark market index, e.g., S\&P 500. In case of underperformance, the fund manager incurred a penalty equal to a percentage of the loss in fund value. Under the latter schedule, the fund manager received a percentage of portfolio assets plus a bonus if the manager outperformed the benchmark. Managers incurred no penalties in case of underperformance. Obviously, advisers of funds following the asymmetric fee schedule might be tempted to take more risk than what is entailed by their clients' profile to outperform the market. Therefore, in an attempt to align the incentive of the investment managers with the incentives of the clients, in 1971, the Securities and Exchange Commission (SEC) prohibited the use of asymmetric performance fee schedules and forced investment companies that were using the asymmetric schedule to shift to the symmetric schedule. One would expect that this move would reduce the risk levels of the funds that were affected by the change. However, on the contrary, Golec and 
Starks (2004) find that the funds that were affected increased their risk relative to the market. Moreover, the funds incurred losses in assets and shareholders during the imposition of restrictions. Their finding is consistent with the theoretical work of Modigliani and Pogue (1975), who argued, based on a simulation exercise, that imposing symmetric compensation performance does not necessarily align the incentives of the manager with the investor; a symmetric performance contract can still motivate the manger to choose a risk level higher than that entailed by his or her client's profile. The work of Ross (2004) and Carpenter (2000) also support this view. They showed that the effects of changing compensation contracts on the manager's choice of risk levels are more complex than the predictable choices. In particular, Ross (2004) showed that changing the convexity of a compensation contract, i.e., changing the options available to an agent does not make him or her more or less risk averse. Theoretical work on the effects of performance incentives on portfolio managers' decisions include, but not limited to, the work of Starks (1987), Heinkel and Stoughton (1994), Ross (2004), and Carpenter (2002). As for empirical work, see for instance, Golec $(1992,1993)$ and Brown et al. (2001).

\section{Portfolio Planning: Understanding the Investor, the Market, and Developing the IPS}

Portfolio planning is considered the first stage in the PMP. In this stage, investment professionals create a roadmap that they then follow to reach the investment goals of their clients. It is crucial in this early stage to make a clear distinction between clients' investment goals and portfolio manager's personal goals. The main objective of constructing any portfolio is to achieve the former rather than the latter. In the end, the money invested is the client's own savings and not the manager's. Being experts in their fields, portfolio managers help their clients achieve their investment goals rather than achieving their personal goals.

The recipe for a successful portfolio manager is a formal document known as the Investment Policy Statement (IPS). In general, this recipe, which is also known as the portfolio mandate, consists of two main ingredients: thorough understanding of the clients' needs and wants and outstanding grasp of the various markets of assets in which they invest. In order to ensure that the client's needs and wants are satisfied, portfolio managers must profile their clients by gathering information on some key factors such as investment objectives, time frame, tax status, and the clients' attitudes towards risk. Among the previous factors, risk tolerance is considered the most important factor in choosing the right portfolio for the investor. As for understanding financial markets, investment professionals, especially those working for large wealth management companies, are backed by an army of analysts, whose job is to pounce on any sort of market information, track trends, and conduct analysis. The reports provided by those analysts to portfolio advisors and managers help them better understanding the market and its trends and enable them to form rational expectations about the behavior of asset prices.

\subsection{Understanding the Investor}

Asset management is considered a client-focused business, and therefore, understanding the investor is the key component that can determine the success or failure of an investment management business. There are two basic types of investors: individual investors and institutional investors. Individual investors, also known as retail investors, are people who invest their own savings on a small scale. Individual investors can create their own financial portfolios by opening personal trading accounts with certified brokers. They can either manage these accounts by themselves or hire investment professionals such as personal financial planners or investment advisors to carry this task on their behalf. Individual investors who do not feel comfortable selecting individual assets themselves or with the help of personal financial planners, can invest via collective investment schemes (CIS) managed by asset management companies. In a CIS, each investor has a claim on the collective investment assets, proportional to the amount invested. CIS have different names and legal structures around the world. Mutual funds, hedge funds, and pension funds are examples of CIS because they pool funds from many investors and manage them collectively by investing in various assets. Mutual funds are usually regulated and are available to both individual and institutional investors. Hedge funds are less regulated and less transparent than mutual funds. Therefore, to protect individual investors from making risky investment decisions, investment in hedge funds is usually only allowed for professional institutional investors. Pensions fund is another example of a CIS that is widely used by individual investors. (Note 2)

Institutional investors are organizations with money to invest either on behalf of their clients or themselves, i.e., their owners or shareholders. In order to manage their investment portfolios, institutional investors either employ investment professionals directly or outsource investment professional services to asset management and investment advisory companies. Institutional investors vary widely by the source of funds and the purpose for managing them. Common major types of institutional investors, their primary business activities, and their typical sources of funds and investment goals are summarized in Appendix A. The Appendix also provides prominent examples of these institutional investors in Canada. In the United States, evidence shows that institutional investors have been successful in managing client assets; see for instance the study of Binay (2005), who argue that during 1981-2002, institutional investors showed significant stock selection skills in the sense that the stocks they selected to include in their portfolios outperformed the 
stocks that they dropped. The top 5 largest institutional investors in each category are summarized Table 1 . Essentially any legal-entity that pools and invests money can be considered an institutional investor. As a result, investment professionals are employed in many parts of the economy. In general, institutional investors can be categorized as either buy-side or sell-side, depending on the nature of their business. Buy-side and sell-side are really just two sides of the same industry. Buy-side institutions work on behalf of themselves or an end client, who has the funds for investment, and seeks to identify worthy securities to buy. Examples of buy-side firms include asset management companies, pension funds, foundations, endowments, sovereign wealth funds and others. Sell-side institutions on the other hand, are concerned primarily with promoting, creating and facilitating the issuance of securities, and ultimately finding buyers to whom to sell those securities. Investment banks are the primary example of sell-side firms.

\subsection{Understanding the Market: Types \& Sources of Information}

A financial market is a forum where buyers and sellers come together to exchange financial products. There are many different types of financial markets and each market is characterized by a distinct set of information. Since the PMP deals with all types of financial markets, it requires a significant amount of up-to-date information in order to be executed properly. Up-to-date information on a particular market helps the investment manager to fully understand that market and, in turn, enhance the PMP process. Overwhelmed with the amount of information and its substantial cost, in terms of both time and money, some investment managers choose to become experts in only a few markets and to focus their investment activities in those markets. To them, the gains from specialization outweigh the costs of diversification.

\subsubsection{Types of Financial Markets}

Financial markets can be grouped into different classifications according to their characteristics. For instance, they can be classified according to product type, liquidity, time period, size, geographical focus, trading schedule, and many other attributes. Four conventional classifications of financial markets usually appear in most finance and economic textbooks, namely: (1) primary and secondary markets, (2) debt and equity markets, (3) exchange and over-the-counter (OTC) markets, and (4) money and capital markets. But, aside from the previous four conventional classifications, in practice, financial markets are usually grouped by the asset classes that are traded on them. Asset classes are broad categories of securities with similar characteristics. With the proliferation of financial engineering, financial instruments are becoming more complex, and some financial instruments possess characteristics of multiple asset classes, in which case they are often called hybrid instruments. Nevertheless, many practitioners tend to group instruments into five primary asset classes, namely, public equity, fixed income, money markets, foreign exchange markets, and alternative investments.

Table 1. Major Types of Institutional Investors and the Top Largest Investors in Each Category

\begin{tabular}{|c|c|c|c|c|}
\hline Institutional investor type & Rank & Name & Country & Relative size \\
\hline \multirow[t]{5}{*}{ 1. Retail and commercial banks ${ }^{*}$} & 1 & ICBC & China & $\$ 2,789$ \\
\hline & 2 & HSBC & UK & $\$ 2,693$ \\
\hline & 3 & Mitsubishi UFJ Financial Group & Japan & $\$ 2,660$ \\
\hline & 4 & Deutsche Bank & Germany & $\$ 2,655$ \\
\hline & 5 & Credit Agricole & France & $\$ 2,650$ \\
\hline \multicolumn{5}{|c|}{ *Ranked by total assets reported in 2013. Source: Fitch Solutions } \\
\hline \multirow[t]{5}{*}{ 2. Investment banks ${ }^{*}$} & 1 & J. P. Morgan \& Co. & USA & $\$ 3.87$ \\
\hline & 2 & Goldman Sachs & USA & $\$ 3.77$ \\
\hline & 3 & Morgan Stanley & USA & $\$ 3.71$ \\
\hline & 4 & Bank of America Merrill Lynch & USA & $\$ 3.52$ \\
\hline & 5 & Citigroup & USA & $\$ 2.75$ \\
\hline \multicolumn{5}{|c|}{ *Ranked by total fees from all underwriting/advisory activities in 2013. Source: Bloomberg } \\
\hline \multirow[t]{5}{*}{ 3. Asset Management Companies ${ }^{*}$} & 1 & BlackRock Inc & USA & $\$ 4,324$ \\
\hline & 2 & Vanguard Group & USA & $\$ 2,753$ \\
\hline & 3 & Allianz Group & Germany & $\$ 2,392$ \\
\hline & 4 & State Street Global Advisors & USA & $\$ 2,345$ \\
\hline & 5 & Fidelity Investments & USA & $\$ 2,160$ \\
\hline \multicolumn{5}{|c|}{ *Ranked by total assets uner management as of year-end 2013. Source: Towers Watson } \\
\hline \multirow[t]{5}{*}{ 4. Pension Funds ${ }^{*}$} & 1 & Government Pension Investment & Japan & $\$ 1,222$ \\
\hline & 2 & Government Pension Fund & Norway & $\$ 858$ \\
\hline & 3 & Stichting Pensioenfonds ABP & Netherlands & $\$ 416$ \\
\hline & 4 & National Pension Service & Korea & $\$ 406$ \\
\hline & 5 & Federal Retirement Thrift & USA & $\$ 375$ \\
\hline \multicolumn{5}{|c|}{ *Ranked by total assets as of year-end 2013 (year-end). Source: Pensions \& Investments / Towers Watson } \\
\hline 5. Insurance Companies ${ }^{*}$ & 1 & Japan Post Insurance & Japan & $\$ 1,139$ \\
\hline
\end{tabular}




\begin{tabular}{|c|c|c|c|c|}
\hline & 2 & AXA & France & $\$ 892$ \\
\hline & 3 & Allianz & Germany & $\$ 806$ \\
\hline & 4 & MetLife & USA & $\$ 800$ \\
\hline & & Prudential Financial & USA & $\$ 625$ \\
\hline \multicolumn{5}{|c|}{ *Ranked by total non-banking assets in 2011 . Source: A. M. Best Research } \\
\hline \multirow[t]{5}{*}{ 6. Foundations ${ }^{*}$} & 1 & Bill \& Melinda Gates Foundation & USA & $\$ 37$ \\
\hline & 2 & Stichting INGKA Foundation & Netherlands & $\$ 36$ \\
\hline & 3 & Wellcome Trust & UK & $\$ 23$ \\
\hline & 4 & Howard Hughes Medical Institute & USA & $\$ 15$ \\
\hline & 5 & Ford Foundation & USA & $\$ 14$ \\
\hline \multicolumn{5}{|c|}{ *Ranked by the size of endowment. Source: www.ranker.com } \\
\hline \multirow[t]{5}{*}{ 7. Endowments Funds ${ }^{*}$} & 1 & Harvard University & USA & $\$ 32$ \\
\hline & 2 & Yale University & USA & $\$ 21$ \\
\hline & 3 & University of Texas System & USA & $\$ 20$ \\
\hline & 4 & Stanford University & USA & $\$ 19$ \\
\hline & 5 & Princeton University & USA & $\$ 18$ \\
\hline \multicolumn{5}{|c|}{ *Ranked by the size of endowment as of June 30, 2013. Source: 2013 NACUBO-Common fund Study of Endowments } \\
\hline \multirow[t]{5}{*}{ 8. Sovereign Wealth Funds ${ }^{*}$} & 1 & Government Pension Fund & Norway & $\$ 893$ \\
\hline & 2 & Abu Dhabi Investment Authority & UAE & $\$ 773$ \\
\hline & 3 & SAMA Foreign Holdings & Saudi Arabia & $\$ 738$ \\
\hline & 4 & China Investment Corporation & China & $\$ 653$ \\
\hline & 5 & SAFE Investment Company & China & $\$ 568$ \\
\hline \multicolumn{5}{|c|}{ *Ranked by total assets under management as of August 2014. Source: Sovereign Wealth Fund Institute } \\
\hline \multirow[t]{5}{*}{ 9. Corporations ${ }^{*}$} & 1 & Fannie Mae & USA & $\$ 3,270$ \\
\hline & 2 & ICBC & China & $\$ 3,125$ \\
\hline & 3 & HSBC Holdings & UK & $\$ 2,671$ \\
\hline & 4 & BNP Paribas & France & $\$ 2,481$ \\
\hline & 5 & Mitsubishi UFJ Financial & Japan & $\$ 2,459$ \\
\hline
\end{tabular}

Description: Major types of institutional investors and the top 5 largest investors in each category ranked by relative size. All figures are in billions of USD.

\subsubsection{Market Information: Sources \& Types}

Market information is at the core of financial analysis and wealth management. Investment management businesses compete to acquire the most accurate and timely market information. Large wealth management firms have armies of analysts who pounce on even the smallest informational advantage at their disposal. On the other hand, due to the large volume of information that is required for proper asset management, it is convenient for some, small scale, investment management businesses to use the service of third party financial data vendors. These companies make a living by providing financial information to different players in the financial system. Examples of these companies are Bloomberg, Thompson Reuters, Fact Set, Markit, Morningstar, S\&P Capital, and many others.

There are many avenues a financial analyst can pursue when shopping for information. In general, market information can come from one of two different sources: primary sources or secondary sources. The former sources include information and data from the annual and quarterly reports prepared by publicly traded corporations as well as from the public conferences calls hosted by these corporations after the publication of their reports. The latter sources include data provided from third parties, e.g., Bloomberg and Standard \& Poor, sell-side analysts' reports, and industry reports.

Market information could be classified in many ways. From a PMP perspective, one can identify three distinct types of information that are relevant to this process, namely, data, news and research. It is possible to distinguish between three types of data that are commonly used for financial analysis. The first type of data is market data, which are historical observations on the behavior of certain financial variables in the market such as prices, rates of return, risk measures, and volatility of different assets and market indices. These observations are recorded daily, hourly, and even every second. Portfolio managers use such historical data extensively to back test their strategies, to attribute investment strategy performance to individual securities, and also to forecast future price movements. There are many providers of market data including individual stock exchanges, e.g., TSX, NYSE, and NASDAQ, financial websites, and financial data vendors. Market data is available continuously throughout the day when trading is taking place in the market. The second common type of data is financial data, which is also known as micro data for it includes financial information about individual companies or issuers of securities such as, earnings, dividends, financial ratios, and so on. This data is used for financial analysis and stock valuation. Both are at the core of fundamental analysis. Finally, the last type of data used in financial analysis is economic data, which is also known as macro data for it includes information about the 
state of the economy such as GDP, interest rates, money supply, unemployment, and other economic indicators. Economic data is used extensively in identifying drivers of stock market performance. This is particularly useful for asset allocation as the aggregate performance of each asset class is usually linked to the performance of certain sectors of the economy.

Professionals, practitioners, academicians, and anyone who has interest in the behavior of financial market, follow its news. The reason is that news gives signals to the public regarding the expected behavior of asset prices, which enable them to form rational expectations regarding the future behavior of these assets. News are particularly important to portfolio managers - so important to the extent that some managers choose to pay third parties for expensive news services in order to get the most accurate and up-to-date version of it.

The third type of information is research, which is basically information that analysts synthesize from other information. There are two basic types of research used in the finance industry: sell-side research and buy-side research. Sell-side research is prepared by sell-side analysts working at financial services companies like brokerages or investment banks, and is usually available to investment managers for a fee or through some other compensation arrangement. Sell-side analysts often issue recommendations for individual securities. Caution must be exercised, however, when following recommendations issued by sell-side analysts because they have incentives to give higher ratings to companies to maintain good business relationships (see, for instance, Beshears and Milkman, 2011). Buy-side research is prepared by the buy-side analysts working at investment management companies and is proprietary. The research is usually kept secret and not shared with anyone until it has become obsolete. Investment management firms need to decide what research to perform in-house and what research can be outsourced to third-party sell-side analysts. Due to the rise of the Internet and to various blogging platforms, several independent research sources have gained popularity. For example, Chen et al (forthcoming) show evidence that crowd-sourced stock opinions on popular financial website, e.g., Seeking Alpha, outperform professional analysts in making their predictions.

\subsection{Investment Policy Statement (IPS)}

Once all of the necessary investor information has been collected and analyzed, investment professionals, using their expertise and their up-to-date market information, begin to formulate the investment objectives and define the investment constraints entailed by their investor's profile. The result is an IPS that outlines the investment strategy, which is tailored specifically for the investor under consideration.

The IPS is extremely important for any investment manager and the reasons are two fold: First, it enables the investment manager to further define the way in which the assets will be managed and allocated in the portfolio. Second, the goals and objectives defined in the policy serve as a benchmark against which the investment manager can assess his or her performance.

Once the investor's profile has been properly analyzed and converted into investment objectives and constraints, the investment manager then begins to device an appropriate investment strategy that meets these objectives and constraints. There are many ways to classify the investment approaches or strategies adopted by portfolio managers. Most textbooks on portfolio management classify these approaches into three common categories, namely, (1) active versus passive approach, (2) systematic versus discretionary approach, and (3) long versus long-short approach. Although the previous approaches are the most common, in practice, however, portfolio performance is a function of the manager's style, which is usually a combination of the manager's experience, expertise, and his or her beliefs regarding certain aspects of markets' behavior. For the sake of completeness, we will briefly discuss the previous three classifications below. However, managers' beliefs is an equally important dimension of a successful strategy, and thus, the factors shaping these beliefs deserve some recognitions.

Some interesting aspects of markets' behavior contributed significantly in shaping the way portfolio managers manage their portfolios. Some of these aspects are well documented in the finance literature such as market timing, short-run momentum, and long-run mean reversion. Market timing refers to the common practice of predicting the movement of a broad market index, such as S\&P 500, and adjusting the portfolio strategy accordingly, e.g., investing the entire portfolio in the market index when it is expected to rise, and putting the entire portfolio in short-term bonds, for instance, when the market is expected to decline. The implication of market timing on portfolio performance can be traced back to the work of Campanella (1972), Sharpe (1975), and Grant (1977). These authors documented evidence of market timing among mutual funds. Other authors, however, see for instance Treynor and Mazuy (1966), did not find any evidence of successful market timing.

Another interesting feature of capital markets is short-run momentum and long-run mean reversion, which refers to the hypothesis that equity returns tend to have a momentum, i.e., tend to continue over short horizons, and then revert to their mean in the long-run. Portfolio managers who believe in short-run momentum and long-term mean reversion can device optimal strategies that hold different portfolios over different time horizons. Evidence of short-run momentum 
and mean reversion can be seen in the work of many authors; see for instance, Fama and French (1988), Lo and Mackinlay (1988), Poterba and Summers (1988), Lo and Mackinlay (1990), Jagadeesh and Titman (1993), and DeBondt and Thaler (1985). The previous studies and many others on the issue of short-term momentum and long-term mean reversion differ in their treatment of the subject; they range from modeling and testing to explaining and analyzing. But, their authors follow one of two schools of thoughts: the efficient markets school and the behavioral finance school. We will discuss both schools in Section 3. As for now, we turn our attention to the most common investment approaches.

\subsubsection{Active versus Passive Approach}

This classification is considered a fundamental distinction between two common strategies to asset management. Portfolio managers following the active approach believe they can outperform the market and derive value by selling over-priced and buying underpriced securities and thus relentlessly seek out the best investment opportunities in the ever-changing financial markets. In other words, proponents of the active approach believe that the market is inefficient. On the other hand, proponents of the passive approach believe the market is already too efficient to allow miss pricing and simply buying and holding the market index or blue-chip stocks will provide better net-of-fees results than active management.

Active investment is usually implemented as a discretionary strategy, which means that, supported by careful analysis, active managers rely on their judgment to make asset allocation and security selection decisions. Part of the investment returns that is attributable to discretionary allocation rather than general market movement is known as alpha, and it can be either positive or negative. Since positive alpha is the goal of all active managers, active approach is sometimes referred to as the "alpha approach." Active management provides a lot of flexibility, but at the same time requires a high degree of expertise. The financial analysis required for active management is also usually more time consuming and expensive than its passive counterpart. An asset manager must maintain a high-quality research team and purchase additional research as needed to help analyze the market and identify investment opportunities. There have been very few well-known successful investors who were able to pick stocks in such a way that their portfolio consistently outperformed the market over a long period of time. Active management is inherently non-transparent, because portfolio managers try not to disclose their active trades and current positions to prevent other market participants from taking advantage of that information. Therefore, from the point of view of investors, performance of active strategies is typically highly unpredictable and cannot be easily explained until the manager makes historical holdings information available. Due to a series of recent high-profile scandals, e.g., Madoff's Ponzi scheme, institutional investors increasingly demand more transparency and accountability from portfolio managers who invest on their behalf. As a result, actively managed portfolios are increasingly under pressure to prove that they add value over passive management. (Note 3)

Passive investors simply try to copy the performance of a market, typically by buying a broad market index, which is an index that includes as many of the securities traded in the market as possible, and holding it for the duration of the investment horizon. A portfolio beta measures how similar the portfolio performance is to the performance of the general market. A portfolio with a beta equal to one means that it is moving perfectly in-line with the market and, therefore, it is a good passive investment. Correspondingly, passive approach to investing is sometimes also called the "beta approach." Passive management is usually implemented via a systematic strategy, which means that all investment decisions are made in accordance with a well-defined algorithm. As a result, passive investing is less time consuming and does not require maintaining a research team as large as that needed for full-scale active investment. Consequently, in terms of fees for the investor, passive investing is significantly cheaper than active investing. It is also more transparent since the performance can be easily compared to that of an observable market index. The focus of passive managers is typically on minimizing the cost of investing in a passive strategy, while still maintaining broad market exposure. The downside of a passive strategy is that it does not have a chance to produce any alpha.

In practice, many managers try to combine the two approaches in some proportion to get some of the benefits from both worlds: the lower cost and higher transparency from a passive approach, and the potential for alpha from an active approach. Their attempts result in hybrid approaches that receive a variety of catchy names such as semi-active, smart beta, beta plus, advanced beta, beta with a portable alpha overlay, and many others. In reality, we must remember that both approaches are fundamentally different and combining them will have advantages as well as drawbacks, so the optimal approach will depend on the investor's talent of design. 


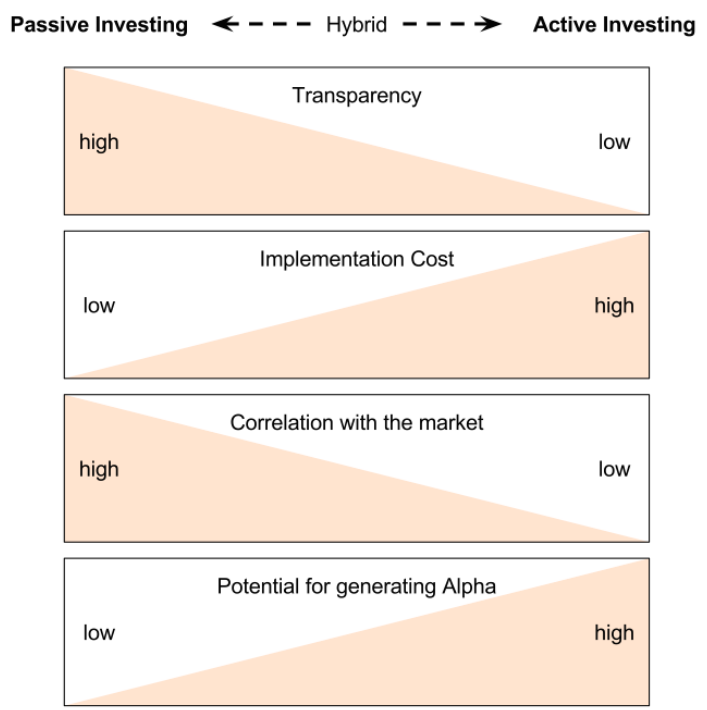

Figure 2. Active versus Passive Investment Approaches.

\subsubsection{Systematic versus Discretionary Approach}

One decision that an investment manager can make when deciding on an investment strategy is either to rely on an algorithm or on an ad-hoc analysis to make investment decisions. As mentioned previously, the former is known as systematic or rule-based approach and the latter as discretionary approach, and they are usually associated with passive and active investing respectively. Nevertheless, discretionary and systematic approaches are subtly different concepts from passive and active investing. Consider, for instance, the case of an alpha seeking mutual fund that systematically invest at the beginning of every month in equal proportions in 10 stocks that pay the highest dividends over the past year. This is an active strategy, where the fund manager uses a systematic approach in which all investment decisions are made in accordance to a well-defined algorithm. Conversely, a passive investor may use a discretionary approach to select a small number of securities that, together, closely resemble the performance of a broad market index.

The benefit of using a systematic strategy is that, if consistently defined, it can be back tested to see what the returns would have been if it was used in the past. The problem with the purely systematic approach is that if a particular strategy is found to be significantly profitable, other portfolio managers could easily copy it. This, in turn, could eventually reduce the profitability of the strategy to the point it no longer outperforms the general market. (Note 4)

The benefit of using passive approach is that it gives manager flexibility with respect to making investment decisions. However, it is not transparent and may result in style drift; a problem that arises when a manager's investment approach deviates too significantly from the original investment goals and the end investors no longer receive the risk exposure they intended to have.

As with active and passive investing, fund managers can combine discretionary and systematic approaches into a new hybrid approach. For example, managers can use systematic models to produce investment recommendations, but then apply their experience and judgment to adjust the result to produce a final portfolio.

\subsubsection{Long versus Long-Short Approach}

Going long is used to express a bullish view that a security is undervalued and its price is expected to rise. On the other hand, going short expresses a bearish view that a security is overvalued and its price is expected to fall. When a value of a portfolio does not react to a price movement of a security, the portfolio said to have no exposure to that security. Analogously, when all positions in a portfolio are aggregated and the net result is that it benefits when the market as a whole moves higher, the portfolio is said to have positive exposure to the market, and vice-versa for negative exposure to markets. Finally, if the portfolio is immune to the overall up or down market moves, it is said to be market neutral. This happens when the combined long and short positions negate each other.

If a portfolio manager wants to sell a security to express a bearish view, but does not already own it, he must borrow the security, sell it, and then buy it back at a later date to return to the counterparty he borrowed it from in the first place. This is known as short selling. Short selling is inherently more risky than buying, because you can loose more than the value of the stock you short-sold, and consequently many IPSs for conservative investors prohibit or limit short selling. Strategies that only take long positions are known as long only or long bias if a small amount of negative exposures is permissible. If a strategy can have both long and short positions in equal proportions, it is called long-short strategy. 
Strategies focusing exclusively on short selling are known as short only, or short bias if a small amount of positive exposure is allowed.

The long only approach is the more traditional and the most widespread approach. However, with the proliferation of financial derivatives and deregulation of financial markets over the past several decades, short selling has become more common. Long-short strategies allow managers to have the most flexibility with regards to isolating and selecting individual exposures in their portfolios. Due to the risks involved in short selling, there are very few short-only strategies and they are used primarily by highly specialized hedge funds. Long-only approach is well suited for passive investing, whereas long-short approach is best suited for active investment.

Before we proceed to the discussion on portfolio construction. We conclude this section by stating a few concluding remarks. First, as the previous discussion suggests, it is clear that there is a wide variety of possible investment strategies. In practice, the successful investment strategy is usually the result of a series of trials and errors performed by the investment professional over time. Second, different strategies may be more suitable for different markets and different clients. Therein lies the importance of portfolio planning. Third, the previous different approaches to portfolio construction, which stem from the investment strategy, define, in a broad way, two processes: financial analysis and asset allocation. Both processes are at the core of portfolio construction, which we now turn to.

\section{Portfolio Construction: Asset Allocation and Security Selection}

Portfolio construction is the second and the most important step of the PMP. This step consists of two stages: asset allocation and security selection. The idea here is that some investment strategies, as defined in the IPS, restrict investment to one asset class, while others allow multiple asset classes. From the point of view of end investors, investing is a multi-asset-class problem, because investing in different asset classes provides diversification, which reduces overall risk. Nevertheless, many investment managers specialize in a single asset class, because end investors tend to divide their portfolio by asset classes and outsource management of each individual asset class to investment managers specializing in that single class. When the IPS entails investment in multiple asset classes, the portfolio construction step begins with asset allocation first; security selection within each individual asset class then follows as shown in Figure 3. On the other hand, if a portfolio has a mandate to invest in a single asset class, security selection is performed right away. But, aside from whether the allocation is executed among the asset classes or the individual securities, the more interesting question is whether or not asset allocation policy has a significant impact on the performance of the portfolio.

The study of Brinson, Hood, and Beebower (BHB 1986) and its update (BHB 1991) emphasize the importance of asset allocation on portfolio performance. In particular, in BHB (1986), using quarterly returns data over the period between 1974 and 1983 for 91 US pension funds, the authors calculated the coefficient of determination from the regression of each fund's total returns on the fund's policy returns and found it to be $93.6 \%$. In the second study of 1991 , they repeated the exercise over the period from 1978 to 1987 for 92 large US pension funds and found that the coefficient of determination is $91.5 \%$. The authors, then, concluded that asset allocation policy is capable of explaining more than $90 \%$ of the variation of a typical fund's average return across time.

Although the BHB (1986) study attracted much attention among practitioners, Ibboston and Kaplan (2000) argue that it is often misinterpreted in answering questions it never intended to address. For instance, the study does not explain the variation of performance among funds. It also does not explain the portion of a fund's return that is due to asset allocation policy. In other words, the BHB (1986) study is suitable when one is interested in studying the significant impact of asset allocation policy on a fund's performance over time. (Note 5) However, to study the variation among funds or the return level, a different model is needed. Ibboston and Kaplan (2000) did exactly that. They, first, answered the question addressed by BHB $(1986,1991)$ and came to the same conclusion. Then, using cross-section regressions, they further answered the question of how much of the variation in returns among funds is explained by differences in asset allocation policies. They found that $40 \%$ of the return difference was explained by asset allocation policy for mutual funds and $35 \%$ by pension funds. They also answered the third question of what portion of fund return is explained by asset allocation policy by computing a simple performance measure, namely, the ratio of compound annual policy return to the compound annual total fund return. A policy/fund return ratio of 1 is indicative to a fund that follows an exact asset policy, i.e., an exact mix of assets, and invests passively. A ratio less than 1 is, on the other hand, indicative to a fund that outperformed its policy. They found that, on average, asset allocation explains approximately $100 \%$ of the level of returns. They, thus, conclude that asset allocation explains about $90 \%$ of the variation of a fund's return over time, $40 \%$ of returns among funds, and about $100 \%$ of the portion of returns.

More recently, Vardharaj and Fabozzi (2007), using a similar technique to the one adopted by Ibboston and Kaplan (2000), found that asset allocation policy explains approximately $33 \%$ to $75 \%$ of the variance in fund returns across funds. Xiong et al (2010) disagreed with Ibboston and Kaplan and showed that the actual percentage of variation of returns among funds is not necessarily $40 \%$. (Note 6 ) 
The criticism that emerged in the finance literature of the significantly high $R^{2}$ value of $93.6 \%$ that was reported by the BHB (1986) study did not deter large institutional investors from continuing to focus most of their attention on their asset allocation policy. After almost 20 years of its publication, L. Randolph Hood, one of the BHB (1986) co-authors, published a short article in 2005 on the debate that have surfaced over time regarding the impact of asset allocation on the variability of returns. After discussing the views of those who are in favor and those who are not, the author concluded, and I concur with him, that the consensus among portfolio managers is that asset allocation policy is indeed among the significant factors affecting the performance of any portfolio. A brief discussion on portfolio performance and the factors affecting it is found in Section 4. As for now, we turn to the theoretical foundations and the practical implementations of asset allocation and security selection.

\section{Investable Asset Base: total wealth that an investor is willing to invest}

Strategic Asset Allocation: long-term target allocation of the investor among various asset classes

Tactical Asset Allocation: short-term deviations from the Strategic Asset Allocation due to market conditions

\section{Security Selection:}

investment in individual securities within each asset class

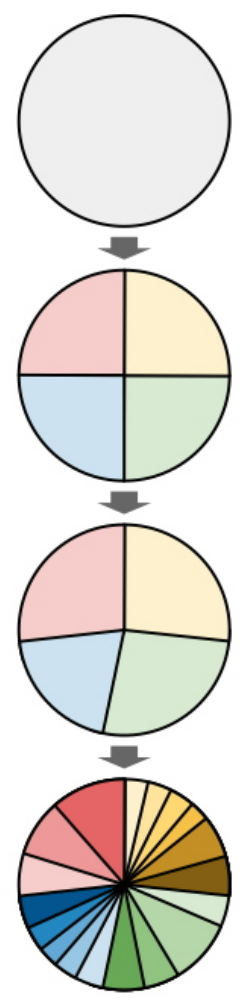

Figure 3. Asset Allocation and Security Selection.

\subsection{Asset Allocation \& Security Selection in Theory}

\subsubsection{Asset Allocation in Theory}

The theory of asset allocation has its roots in the work of Harry Markowitz (1959), who studied the investor's portfolio decision problem, which, according to Markowitz, is to choose optimal weights of individual assets in a given portfolio such that the variance of the rate of return of the portfolio is minimized for a given expected return. Mathematically, this is a constrained optimization problem, where the objective function that needs to be minimized is the variance of a given portfolio $p$, denoted by $\sigma_{p}^{2}$, and defined as $\sigma_{p}^{2}:=\operatorname{var}\left(r_{p}\right)$, where $r_{p}$ is the rate of return on the portfolio, which is the weighted sum of the rates of return on the individual assets forming it; that is,

$$
r_{p}=w_{1} r_{1}+w_{2} r_{2}+\cdots+w_{n} r_{n}
$$

where $w_{i}$ is the weight of asset $i$ in the portfolio. The constraint is a target expected rate of return $\mu_{p}$, and the decision variables are the portfolio weights $w_{i}$, for $i=1, \ldots, n$, where $n$ is the number of assets in the portfolio. Putting all this together, the portfolio problem is

$$
\min _{\left\{w_{1}, \ldots, w_{n}\right\}}=\sigma_{p}^{2}, \text { subject to } E\left(r_{p}\right)=\mu_{p} .
$$

Harry showed that the solution to this problem is a locus of risk and return combinations that yield the minimum portfolio variance for a given rate of return. This set of minimum variance portfolios is known as the minimum variance frontier, which can be generated by solving the Markowitz problem in (2) for different values of $\mu_{p}$. The result is a hyperbola in the mean-standard deviation space as depicted in the Figure 4. The dashed part of the hyperbola is the efficient frontier. The point MVP is the minimum variance portfolio. First notice that any point inside or along the 
hyperbola in Figure 4 is a portfolio of assets. However, not all points are desirable. Since any rational investor prefers more expected return for the same risk or less risk for the same return, i.e., any investor will be better off if he or she chooses portfolios located to the North West in Figure 4, and since the minimum variance frontier is the solution to Markowitz's problem, then all portfolios located on the upper leg of the minimum variance frontier, i.e., the upper leg of the hyperbola in Figure 4, are more preferred than any other portfolios. That's why that part of the minimum variance frontier is called the efficient frontier for it gives the set of mean-variance choices from the minimum variance frontier where, for a given portfolio variance, no other investment opportunity offers a higher expected return. Note also that there is only one portfolio in the set of efficient portfolios that yields the absolute minimum variance. This portfolio corresponds to the vertex of the hyperbola and is known as the minimum variance portfolio (MVP).

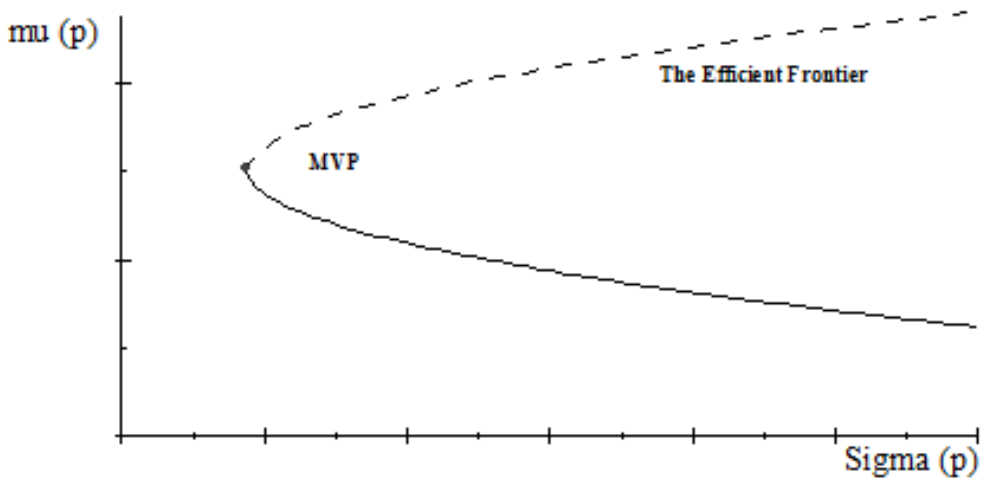

Figure 4. In case of $n$ risky assets, the minimum variance frontier is the hyperbola drawn in $\mu_{p}-\sigma_{p}$ space.

Adding a risk-free asset, e.g., a government bond, to the $n$ risky assets makes the minimum variance frontier linear instead of a hyperbola drawn in $\mu-\sigma$ space. In particular, the minimum variance frontier in case of one risk-free asset, $r_{f}$, and $n$ risky assets is the straight line originating from the risk-free rate, which is point A on the vertical axis in Figure 5, and going up to the tangency portfolio T, i.e., the point of tangency between the line AT and the hyperbola.

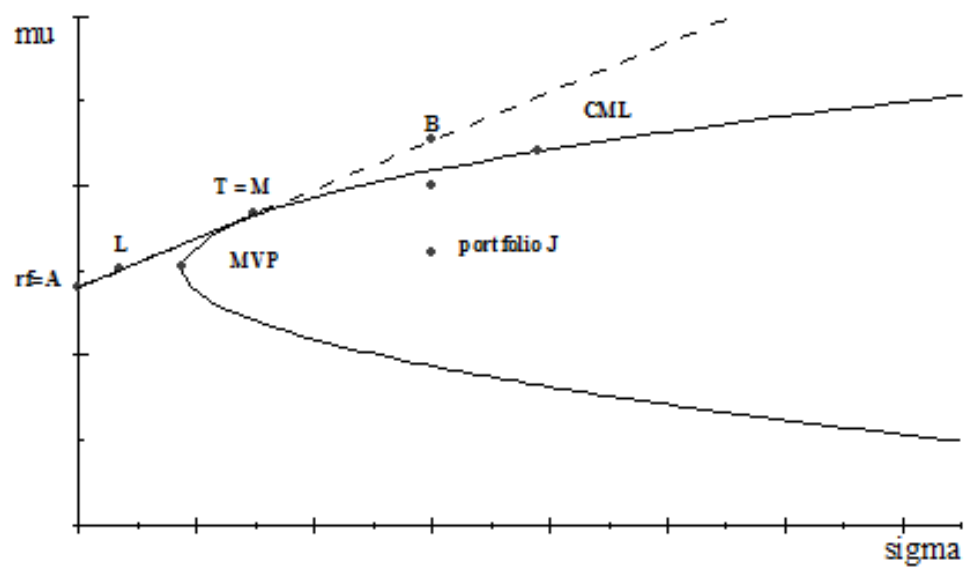

Figure 5. The efficient frontier is the upper leg of the hyperbola originating from the minimum variance portfolio (MVP) in case of $n$ risky assets. In case of $n$ risky assets and one risk-free, the efficient frontier is the straight line AT.

To see why AT is the minimum variance frontier in case of $n$ risky assets and one risk-free, note that once we introduce the risk-free asset, any investor is faced with the choice of combining the risk-free asset (point A) with any portfolio of $n$ risky assets of his or her choice. Since the points on the upper leg of the hyperbola correspond to efficient portfolios, any investor will definitely combine A with one of these points. This creates potentially many possible portfolios; each is represented by a straight line originating from point $\mathrm{A}$ and ending at one point on the upper leg of the hyperbola in Figure 5. However, since any investor will be better off if he or she moves to portfolios located on the North West, then all investors will be willing to combine the risk-free asset with the tangency portfolio $\mathrm{T}$. This is true since $\mathrm{T}$ is the farthest attainable North West portfolio. This means that only line AT dominates all other combinations and, therefore, it is the efficient frontier in this case. It is worth mentioning that, in practice, the efficient frontier is known as the Capital Market Line (CML).

The point that we did not discuss so far is the reason behind introducing a risk-free asset in the portfolio analysis. The risk-free asset is introduced in order to create an exchange or a market economy in which agents are able to borrow and lend unlimited amounts at the risk-free rate. The idea here is that in order to model a market where investors can borrow 
and lend, we need a rate of return at which the borrowing and lending operations can be conducted. This rate is the risk-free rate of return. The introduction of the risk-free asset implies that investors in the capital market must mix one risk-free asset with a portfolio of $n$ risky assets to construct their efficient portfolios. This implies that every investor, regardless of his or her degree of risk aversion, will choose to mix the risk-free asset with the tangent portfolio $\mathrm{T}$. This is true for any rational investor in the capital market. If we assume that all investors are rational, then all of them will try to combine portfolio $\mathrm{T}$ with the risk-free asset. This implies that the tangent portfolio $\mathrm{T}$ is the market portfolio, which is denoted by $\mathrm{M}$ in Figure 5.

If we further assume that investors in this capital market can borrow and lend at the risk-free rate, then we must extend the efficient frontier all the way up and above point $\mathrm{M}$ (see the dashed extended part in Figure 5) to allow for possible choices for borrowers. The previous discussion implies that all efficient portfolios can be constructed by combining the risk-free asset and the tangency portfolio. The previous result is a statement of Tobin's (1958) Separation Theorem. (Note 7)

If the previous two assumptions hold, i.e., if investors are risk averse and if they only care about the mean and variance of their portfolios, then, by combining a risk-free asset with $n$ risky assets, any investor can solve the Markowitz problem and find the optimal portfolio weights that minimize the variance of his or her portfolio. The solution to this problem yields a vector of optimal weights of the assets forming the portfolio. These optimal weights are considered the outcome of asset allocation. Once the optimal weights of various asset classes are determined, the next step is to populate each asset class by selecting an optimal number of securities. The choice of securities within a class of asset involves a statement regarding the fundamental value of the security, which in turn, is a function of its price. Thus, the process of price formation (from an academic point of view) and the prediction of the price movements (from a practical point of view) are crucial to security selection.

\subsubsection{Security Selection in Theory}

Financial analysis is at the core of security selection. It can be viewed, in general, as the process of analyzing and understanding the behavior of financial time series in capital markets. On the theoretical frontier, academicians contributed equilibrium models that aim to describe the process of price formation in the financial markets. The first formal financial model, as discussed in the previous section, was due to the work of Harry Markowitz (1959). Soon after the introduction of Markowitz's portfolio theory, a simple price formation model that explains the risk-reward relationship for individual assets or portfolios of assets was introduced. The model, which is known as the Capital Asset Pricing Model (CAPM), was originally developed by Sharpe (1964) and further extended and clarified by Lintner (1965).

The result of Markowitz's model is a condition that gives the optimal assets' weights in mean-variance efficient portfolio. The CAPM of Sharpe (1964) and Lintner (1965), or the standard CAPM adds two key assumptions to Markowitz's model; namely, (1) all investors have the same beliefs regarding the joint distribution of asset prices, and hence returns, at time $t$, given the observed asset prices at time $t-1$, (2) all investors can borrow and lend at the same risk-free rate. The assumptions of Markowitz's model and the previous two assumptions together imply that all investors perceive the same efficient frontier. This, in turn, implies that all investors will combine the risk-free borrowing or lending with the tangency portfolio $\mathrm{T}$. Since portfolio $\mathrm{T}$ is held by all investors, it must the market portfolio M. (Note 8) The CAPM then implies that, if the market is efficient, i.e., if the asset market is to clear, then the market portfolio $\mathrm{M}$ must be on the minimum variance frontier. This, in turn, implies that the linear efficient set originating from point $\mathrm{A}$ and passing by the portfolio $\mathrm{M}$, i.e., the $\mathrm{CML}$, is characterized by the following linear equation:

$$
E\left[r_{p}\right]=r_{f}+\left(\frac{E\left[r_{M}\right]-r_{f}}{\sigma_{M}}\right) \sigma_{p},
$$

For any efficient portfolio $p$, where $E\left[r_{M}\right]$ is the expected rate of return on the market portfolio. The CML equation in (3) establishes the relationship between risks and expected returns for efficient portfolios of assets. But, what about the relationship between risks and returns for individual assets? The answer to this question lies in a measure of risk known as the market beta of the individual asset (Note 9), which is a measure of the risk contribution of asset $i$ and is denoted by $\beta_{i M}$. The CAPM posits that there exists a linear relationship between the expected rate of return on asset $i, E\left[r_{i}\right]$, and its risk. The intuitive explanation favored by all practitioners in the industry is as follows. The expected rate of return that an investor wishes to realize on a risky asset $i$ is the expected rate of return on assets that have zero market beta, i.e., the expected rate of return on assets that are uncorrelated with the market, which we will denote by $E\left[r_{Z M}\right]$, plus a premium for the risk that the investor has to tolerate as a result of holding asset $i$. This risk premium is the amount of risk due to asset $i$, which is $\beta_{i M} \sigma_{M}$, times a general price of risk, which is the market premium defined as the excess return of the market portfolio over the expected rate of return on assets that are uncorrelated with the market 
$\left(E\left[r_{M}\right]-E\left[r_{Z M}\right]\right)$ relative to the market risk $\sigma_{M}$; that is,

$$
E\left[r_{i}\right]=E\left[r_{Z M}\right]+\beta_{i M} \sigma_{M}\left(\frac{E\left[r_{M}\right]-E\left[r_{Z M}\right]}{\sigma_{M}}\right),
$$

where the ratio $\left(\frac{E\left[r_{M}\right]-E\left[r_{Z M}\right]}{\sigma_{M}}\right)$ is known as the Sharpe Ratio. Simplifying the expression in (4) by cancelling out $\sigma_{M}$

that appears in the numerator and the denominator yields

$$
E\left[r_{i}\right]=E\left[r_{Z M}\right]+\beta_{i M}\left(E\left[r_{M}\right]-E\left[r_{Z M}\right]\right) .
$$

Finally, the assumption of risk-free borrowing and lending implies that the expected return on assets that have zero correlation with the market, $E\left[r_{Z M}\right]$, must equal the risk-free rate, $r_{f}$, and hence, the standard CAPM of Sharpe and Lintner in equation (5) becomes the following more familiar specification

$$
E\left[r_{i}\right]=r_{f}+\beta_{i M}\left(E\left[r_{M}\right]-r_{f}\right) .
$$

Because equation (6) is based on the unrealistic assumption of risk-free borrowing and lending, Fisher Black (1972) was able to obtain the same result of Sharpe and Lintner without the risk-free borrowing or lending assumption. But, regardless whether it is Black's version or the standard version, the ultimate use of CAPM is to compute the required rate of return on any risky asset, which in turn, can be used to compute its price.

Although the CAPM is intuitively appealing, its empirical validity is questionable. Like any theory, one way to test how it works in practice is to test the validity of its assumptions. When put to the test, the CAPM's empirical performance was so poor to the extent that it was rendered invalid. (Note 10)

In 1976, the economist Stephen Ross suggested another more general and more testable alternative to CAPM. Unlike CAPM, which suggests that the rate of return on any security is linearly related to a single factor, which is the rate of return on the market portfolio, Ross's theory, which is known as the Arbitrage Pricing Theory (APT), asserts that the variation in the rate of return of a security can be explained by its sensitivity to a number of factors. This last statement is a statement about factor models, which are considered the building block of the APT. The idea here is that the rate of return on a security depends on market variables and firm-specific variables. The former are economic variables that have influence on the economy, the market, and, in turn, the rate of return on the security under consideration, e.g., changes in interest rate, changes in inflation, technological changes, and business cycle fluctuations, whereas the latter are firm related shocks, known as idiosyncratic shocks, such as defective products, harmful products, bad publicity, reputation, and poor management.

In addition to market factors and firm-specific factors, recent evidence shows that other factors, than the stock market beta suggested by CAPM, seem to have an explanatory power in explaining the variation of the expected rate of return on a stock. Basu (1977) discovered an earning-to-price (E/P) ratio effect. In particular, Basu showed that when common stocks are sorted on E/P, future returns on high E/P stocks are higher than predicted by CAPM. Banz (1981) reported a size effect; when stocks are sorted on market capitalization, average returns on small stocks are higher than predicted by CAPM. Bhandari (1988) reported a leverage effect; high debt-to-equity ratios are associated with returns that are too high relative to their market betas. Statman (1980) and Rosenberg, Reid, and Lanstein (1985) showed that stocks with high book-to-market equity ratios have high average returns than the returns suggested by their beta coefficients.

The evidence brought by the previous studies confirms that the standard version and the black version of the CAPM suffer from fatal problems. The failure of CAPM as an equilibrium theory of price formation prompted researchers to turn to explanations. The equilibrium that I am referring to here is the financial equilibrium in the capital market, where the demand for financial assets is equal to the supply. In fact, Markowitz's model, CAPM, and even Ross's APT, assume that all asset prices clear the markets of all assets. The models, unfortunately, do not explain or derive this financial equilibrium; rather they assume that it is the result of market efficiency. This hypothesis is known as the efficient markets hypothesis (EMH), which posits that capital markets are ideal in the sense that, at any point in time, security prices in any market fully reflect all available information in that particular market. (Note 11)

In general, two explanations appear in the literature: one explanation of the failure of the CAPM entertains the fact that the model is based on many unrealistic assumptions and, thus, a more complicated model of price formation is needed. Advancements on this frontier made use of various types of micro-founded models in explaining the behavior of investors and in deriving equilibrium conditions in all markets. (See, for instance, Campbell and Cochrane (1999), Constantinides (1982), Epstein and Zin (1989), Lucas (1978), Mankiw and Zeldes (1991), and Mehra and Prescott (1985).)

The other explanation is due to the behaviorists. They brought recent evidence from behavioral finance and 
neurosciences to demonstrate that the market is inefficient. Their rationale is that investors, especially retail traders, exhibit irrational behavior in constructing portfolios and conducting their trades in the market. This irrational behavior causes asset prices to over or under value their fundamental values rendering the market inefficient. Andrew Lo (2004) surveyed the literature on the debate between the advocates of the EMH and behavioral finance and suggested reconciliation between both approaches. His reconciliation hypothesis, which he called "the Adaptive Markets Hypothesis," posits that the inefficiency in the market is due to the irrational behavior of investors, but since investors adapt to the changing environment, their adaptability over time brings the market back to efficiency.

The previous recent attempts, elegant as they were, did not attract the attention of practitioners in the financial market. To this very day, despite its poor empirical performance, the CAPM is the most favorite asset-pricing model among practitioners in the finance industry. This is due to its simplicity and intuitive appeal as opposed to the fairly complicated recent general equilibrium models.

\subsection{Asset Allocation \& Security Selection in Practice}

\subsubsection{Asset Allocation in Practice}

Having looked at the theory, we now turn to answering the question of how the theory works in practice? As we discussed earlier, the MVP theory is based implicitly on the EMH, which does not hold all the time. Therefore, in practice, the inefficiency in the market and the irrational behavior of some retail investors create profit opportunities that can be harvested by any savvy financial manager. This suggests that some portfolio managers are able construct portfolios that lie northwest even further than the market portfolio located on the efficient frontier AM in Figure 5. In other words, some are able to beat the market.

In practice, it is common to distinguish between two types of asset allocation. The first type of allocation, which is known as asset-only allocation, focuses exclusively on investments and does not explicitly account for other assets or liabilities that the investor might have. The second type of asset allocation, known as asset liability management (ALM), does consider the total financial position of the investor and analyses investments in the context of how those investments would perform in combination with other assets and liabilities that the investor might have. Asset-only allocation is the traditional asset allocation that we are all used to. It is simpler than ALM, requires less data, and is the most useful approach when other liabilities and assets are unknown and can not be predicted or estimated ahead of time. The asset-only approach is often used by individual investors, endowments, foundations, and most other investors. ALM is a more comprehensive approach, because it emphasizes the need for investors to consider all of their financial position on an aggregate basis, and therefore it is also more complex. ALM focuses on optimizing risk and return of the surplus, which is the difference between assets and liabilities of the investor. In order to effectively implement ALM, accurate and timely information about both assets and liabilities is required, so investors who use it tend to be the more sophisticated investors who have the necessary systems in place for collecting and analyzing relevant data. ALM is used most often at banks, insurance companies, and large pension's funds. All three share the common objective of investing their assets in order to cover their projected liabilities.

Asset allocation is performed with respect to individual asset classes. To be considered an asset class, a group of securities must be similar and react consistently to the same macroeconomic drivers. For example, overall equities react positively to strong nominal GDP growth. Likewise, bonds typically perform best when interest rates are low. If carefully selected, combining asset classes should result in diversification benefits; that is, the risk-adjusted returns will be higher for optimal portfolio of combined asset classes than the risk-adjusted returns of any asset class taken individually. One other consideration for choices of asset classes is that they must be investable, which means there must be a sufficiently large market for securities, which can be purchased to gain exposure to an asset class. For example, exotic instruments like weather derivatives may not be investable for individual investors because they usually require high minimum notional amount. Some emerging equity markets are also not considered investable from the point of view of large institutional investors because they may not be allowed to access those markets due to local regulations, or because these markets are not large enough to accommodate a minimum investment amount that a large institutional investor may want to commit. However, sometimes, it may be possible to select proxies; securities that behave similarly to securities in a particular asset class, but are more liquid and therefore investable. For example, it may not be feasible to buy several properties in order to get exposure to real estate asset class. However, it is possible to use Real Estate Investment Trusts (REITs) as proxies because they have good liquidity and their performance is similar to that of direct real estate assets. Some investors may be restricted in their ability to invest in specific asset classes for variety of reasons, which would be stated in the IPS. All of these factors must be taken into account when deciding which asset classes will be included in the asset allocation step.

Performance of asset classes is captured by various market indices, which are just time series of values corresponding to the systematically combined performance of all securities in a particular group. Perhaps, the most well-known index among practitioners in the finance industry is the Standard \& Poor's 500 (S\&P 500), which represents cumulative 
performance of 500 largest companies listed on NYSE or NASDAQ weighted by the market value of their traded stock, market capitalization.

Two methods are usually used for asset allocation: quantitative and qualitative. The former methods are disciplined approaches with formal foundation in mathematics and statistics, e.g., optimization and simulation, and hence, more preferred over the latter methods, which are rather crude and subjective. In any case, whether qualitative or quantitative, these methods are just tools and the reliability of the results they produce will depend, among many factors, on the quality of the data supplied, how well the problem was framed and whether or not all of the relevant factors were adequately considered.

Perhaps the most well-known optimization procedure used at the core of most quantitative approaches to asset allocation is Markowitz's (1959) optimization, which is also known as the mean-variance optimization (MVO) technique. In its basic form, it can produce the efficient frontier and determine the optimal mix of assets that yields the maximum expected Sharpe ratio, which is the most common measure of risk-adjusted return. MVO requires several inputs to get started. But, first, the manager must decide what asset classes should be included in the MVO procedure. Selecting all of the major asset classes is usually a good starting point. Adding alternative asset classes may further improve diversification. Blume (1984) suggested a simple formula that can be used to decide whether or not adding an asset class to an optimal portfolio of existing asset classes will result in improved efficient frontier and new maximum Sharpe ratio. Blume's simple result says that, in order to add a new asset class $N$, to an existing optimal portfolio $P$, the Sharpe Ratio of the new asset class, $S_{N}$, must be larger than the Sharpe Ratio of the optimal portfolio, $P_{N}$, times the correlation between the rate of return on the new asset class and that on the optimal portfolio, $\rho\left(r_{N}, r_{P}\right)$; that is,

$$
S_{N}>S_{P} \times \rho\left(r_{N}, r_{P}\right) .
$$

Among the other factors that should be taken into account when deciding whether or not to add a new asset class, one can mention the trade ability of the asset class, the costs associated with investing in it, and the managers' ability to analyze and make predictions with regards to that new asset class. It is important to note that the selection of asset classes to be included in the MVO must be done in accordance with the IPS and can only include asset classes allowable within the mandate approved by end investor.

Next, the manager must define specific constraints with respect to each of the asset classes. If leverage is not allowed, then there must be a so-called budget constraint restricting the sum of the weights of all individual asset classes to one. For long-only portfolios, where all weights must be positive, the non-negativity constraint should be applied to all asset classes. Other constraints are possible based on the circumstances of a particular investor. Sometimes, when a portfolio must maintain some level of liquidity for distributions to investors, illiquid asset classes, e.g., physical real estate, are assigned a maximum weight constraint. In other cases, when a manager wants to maintain a minimum allocation to an asset class to ensure it is represented in the final allocation, a minimum weight constraint may be appropriate. Once the list of asset classes has been established, MVO requires two inputs: a vector of expected returns for each of the asset classes and the expected variance-covariance matrix. The easiest approach is to use historical average returns over a sufficiently long period as estimates of the expected returns as well as historical variances and covariances over the same period as estimates for the expected variance-covariance matrix. However, these estimates can and should be adjusted if the investment manager believes he can improve them, because the accuracy of the inputs is the key to a successful outcome of optimization. At this point, the inputs can be passed to the MVO procedure. Executing the MVO produces the efficient frontier from which the tangency portfolio and the Capital Market Line can be determined. The final step is to select an appropriate portfolio. The choice of an optimal portfolio must directly address the investment objectives from the IPS. Investment objectives are most often translated into one of three optimization problems: either to maximize expected return given maximum allowable risk, or to minimize risk given a target expected return, or to maximize the Sharpe Ratio; that is maximize expected return per unit of risk. The tangent portfolio is the optimal portfolio for the latter problem. The optimal portfolio for the former two problems depends on whether or not investing in risk-free assets or borrowing is allowed. If the investor is not able to invest in risk free assets or borrow money for investment, then the optimal portfolio will lie on the efficient frontier. Otherwise, if the investor is able to hold risk free assets and can also borrow for investment, the optimal portfolio will lie on the CML. Figure 6 summarizes the procedure involved in basic MVO.

Despite being a very disciplined approach, MVO has a number of downsides. The main problem is that MVO is very sensitive to expected returns and variance-covariance inputs. In order to produce reliable forecasts from historical data, a sufficiently large time-series of observations is needed. However, financial data for certain asset classes, particularly more exotic ones, can be limited. For example, the market for dim sum bonds, which are bonds denominated in Chinese Yuan, was only formed in July of 2007. Another significant drawback of the simple MVO approach is that if one of the asset classes has significantly better historical risk-adjusted returns than others, it could be significantly over-represented. This behavior may be desirable, but often it results in under-allocation to other asset classes and 
overexposes the portfolio to systematic risks of the over-allocated asset class. Since past performance does not guarantee future performance, it may be unwise to put all savings in one asset class, even if it has the best risk-adjusted returns based on historical performance.

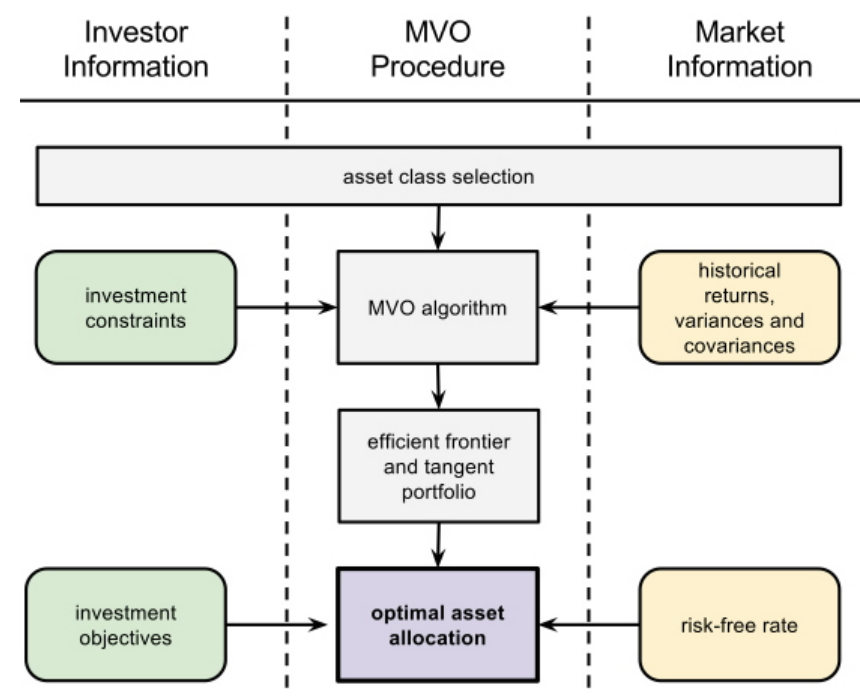

Figure 6. The Mean-Variance Optimization in Practice.

Due to the deficiencies of the traditional MVO approach, numerous ways to improve the MVO procedure to produce more reliable and diverse allocation have been proposed by practitioners in the industry. One way is to experiment with different inputs and build several efficient frontiers instead of one. This procedure is often known as MVO with resampling. The result is a range of optimal outcomes based on different return and variance-covariance inputs that would allow portfolio managers to gage the sensitivity of the MVO approach to those inputs. This procedure allows better understanding of the effect of measurement errors in the inputs on optimal allocation and may enable portfolio managers to come up with a more robust asset allocation that would perform well in a variety of potential scenarios.

Another popular way to improve the traditional MVO is the so-called Black-Litterman (BL) model, which was first published in 1992 by Fisher Black and Robert Litterman. BL recognizes the weakness of using historical estimates in order to arrive at the optimal allocation for the future and tries to address it indirectly. The approach first reverse engineers the implied expected returns, also known as equilibrium returns, for assets assuming the markets are in equilibrium and the current proportional market capitalization of each asset class represents the equilibrium weights. The model then provides methodology to adjust equilibrium returns up or down in accordance with the portfolio manager's views, taking into account the level of conviction for each view. The adjusted equilibrium returns are then fed back into an MVO procedure. The result is usually a well-diversified portfolio where allocation is more intuitive and, in the absence of any views, consists simply of the equilibrium market weights.

Finally, several qualitative allocation or "short-cuts," also referred to as experience-based approaches, have become quite well known in the industry. These apply primarily to individual investors and are popular for their simplicity. One such approach, which is known as the " $60-40$ " rule, is to assume that the allocation of $60 \%$ in equity and $40 \%$ in bonds is the neutral allocation, suitable for an average investor. If an investor has above average ability and willingness to take risk, then the initial 60-40 could be adjusted to have more equity and less bond exposure. Conversely, if the investor has below average risk tolerance, $60-40$ could be adjusted to have less equity and more bond exposure. Another popular rule of thumb is the "100-age" rule. This rule suggests that the allocation to equity in percent terms should be equal to 100 minus a person's age, and the rest should be allocated to fixed income. This implies that with time, as the person ages, the optimal allocation to fixed income should increase and allocation to equities decrease. This makes intuitive sense because as people age, we expect their risk tolerance to decrease.

Once asset allocation has been determined, it is time to decide how to populate individual securities within each asset class. This is the subject matter of the following section.

\subsubsection{Security Selection in Practice}

Practitioners in the finance industry believe that financial time series can be forecasted. As opposed to academicians, practitioners are not interested in developing models of price formation; rather they are interested in developing techniques to analyze and predict the price movements of financial assets in order to seize any profit opportunity that might arise from overvaluation or undervaluation of asset prices. In general, there are two approaches to security selection in practice: The top-down approach and the bottom-up approach. The former involves first determining the 
high-level allocation to various categories or subgroups of securities and then determining allocation to individual securities within each subgroup. The latter is the opposite: analysis is first performed on individual securities and then an overall portfolio is constructed based on the outcome of that analysis. The top-down approach is more common with passive strategies for it allows selecting exposures to different sectors of the market in the same proportion as in the market. Doing so ensures that the portfolio is exposed to the same risks in the same proportion as the market. This, in turn, makes it more likely that the portfolio will closely track the market. On the other hand, the bottom-up approach is more suited for active investing, because it allows to identifying mispricing opportunities among individual investments. It is possible to attempt to use both approaches together in order to get a more complete picture for the security selection process.

Focusing on the techniques adopted by practitioners in the finance industry in performing financial analysis, one can observe two schools of thought: the fundamental analysis school and the technical analysis school. Although both schools share the same objective, which is to give advice on what and when to buy and sell assets for the sake of making profit, they differ in their ways of analysis. The proponents of the fundamental analysis believe that any asset has a foundation value or an intrinsic value. Due to market conditions, the actual price of the asset fluctuates continuously around this intrinsic value; it could fall below or rise above this value. This fluctuation implies that the actual market price of the asset will eventually reach its intrinsic value but will rarely remain at it. This, in turn, creates buying and selling opportunities when the asset is undervalued or overvalued respectively. Finding the intrinsic value of the asset under consideration is the main objective of fundamental analysts. The proponents of technical analysis, on the other hand, believe that the study of past price movements helps in predicting its future movements. The general consensus among technical analysts is that fundamentals are irrelevant because all market information are reflected in the price process, and thus, studying the past behavior of the price series is the best way to predict its future movements. We begin by analyzing the first school of thought; the fundamentalists.

\subsubsection{Fundamental Analysis}

Fundamental Analysis has its roots in the firm-foundation theory, which asserts that any asset, i.e., a common stock, a real estate, or even an investment project, has a foundation value or an intrinsic value. Due to market conditions, the actual price of the asset fluctuates continuously around this intrinsic value; it could fall below or rise above this value. This fluctuation implies that the actual market price of the asset will eventually reach its intrinsic value but will rarely remain at it. This, in turn, creates buying and selling opportunities when the asset is undervalued or overvalued respectively.

Since many people during the early 1930s contributed to the idea of comparing the actual value of an asset to its true underlying value, i.e., its intrinsic value, the firm-foundation theory was not accredited to one individual. The first formal version of the theory was due to the economist John Burr Williams, who proposed in 1938 a theory of investment value, which postulates that the intrinsic value of an asset can be determined by discounting all its expected future cash flows. In particular, Williams pioneered the dividend valuation of stocks by proposing the rule of present worth, which states that intrinsic worth of a common stock is the present value of all its future expected dividend payments (cash flows). Later in 1956, Myron J. Gordon formulated Williams' theory into a valuation equation known as the Gordon growth model. Today, Gordon model is considered the standard model for stock valuation among practitioners in the finance industry.

Surprisingly, the work of Williams (1938) did not get much attention at that time. It did not really become popular until Ben Graham and David Dodd developed their value investing approach and published their book titled "Security Analysis" in 1934. Their idea of value investing is to perform some sort of fundamental analysis that reveals whether or not the asset under consideration is undervalued or overvalued. Their recommendation is to buy the undervalued asset and sell the overvalued one. In this book, Graham suggested to perform fundamental analysis for each individual security by analyzing all the micro variables affecting the firm itself and the industry in which it is operating. Later, in 1949, Graham published a second book titled "The Intelligent Investor," where he refined his own old views and advised to focus more on trying to buy groups of stocks that meet some simple criterion for being undervalued regardless of the industry and with very little attention to the individual company. Graham's value investing view, which has the idea of buying stocks that are traded at less than their intrinsic value at its core, was celebrated by many successful financial practitioners in the industry including Warren Buffett, the chairman of Berskshire Hathaway. (Note 12)

Fundamental Analysis is nothing but a valuation method of an asset, which is usually taken to be an investment project or a corporation. Therefore, when we talk about fundamental analysis of a stock, a firm, or an investment project, we are referring to the process of valuing such assets.

Valuation is a key concept in finance. It is used in finance theory, portfolio management, corporate finance, and capital theory. In a broad sense, the approaches to valuation can be categorized into three general approaches: (1) The 
discounted cash flow (DCF) approach, were the asset under consideration is valued by discounting its future expected cash flows using an appropriate discount rate. (2) The accounting valuation or liquidation approach, where the corporation is valued by assessing its existing assets using accounting estimates. (3) The relative valuation approach, where the value of an asset is calculated by looking at the value of "comparable" assets relative to a common variable such as earnings or sales. The second and the third approaches are used in specific circumstances whereas the first approach is the most widely used and, for that reason, it will be the focus of our analysis. (Note 13)

The DCF Valuation approach treats an asset as a going concern and aims to find the present value by discounting its expected future cash flows using an appropriate discount rate. The word "appropriate" here means a discount rate that reflects the degree of riskiness of the underlying asset. Out of the previously mentioned valuation approaches, the DCF approach is the most comprehensive, well developed, and extensively used among practitioners and academicians in the finance industry. Before we introduce the DCF approach and discuss its variants, below is a survey of its historical development.

The roots of the DCF approach can be traced back to the development of the rule of present value and interest tables. In an excellent survey on the development of the DCF criteria before 1950, Parker (1968) argues that one of the early interest tables, which was developed back in 1340, is due to Francesco Balducci Pegolotti, who prepared them for Florentine firm of the Bardi in a manuscript that was not published until 1766. The early formal study that laid the basis of the present value rule, which was basically a text in financial mathematics, is due to the mathematician Simon Stevin in a book titled "Tables of Interest." The book was published in Antwerp in 1582. Simon explained and defined simple and compound interest rates and explained the basis of the present value rule in his textbook.

Although, as mentioned in Parker (1968), many contributions to the concept of discounting future cash flows in various applications came from different disciplines such as engineering and actuarial science, it is the work of Marshall (1907), Bohm-Bawerk (1903), Wicksell (1954), and the notable work of Fisher (1907) on capital theory that shaped our understanding of the DCF valuation. Marshall (1907) explained the usefulness of the present value rule in discounting future outflows and inflow of capital. He pointed that when discounting these cash flows, allowance should be made to the risk of failure of the investment capital under consideration. Bohm-Bawerk (1903) used the problem of buying a house for the payment of 20 installments of 1,000 florins each to illustrate the application of net present value. The most notable work on capital theory and DCF valuation is due to Fisher, who published his work in a Book titled "The Rate of Interest" in 1907. The book was extensively revised in 1930 and published under the title "The Theory of Interest." In his books, Fisher suggested four ways of choosing between investment alternatives. The net present value (NPV) criterion and the internal rate of return (IRR) criterion were among the four suggested alternatives. Nowadays, both approaches are considered standard practices and routinely used among practitioners in the finance industry. Although Fisher discussed a variant of the IRR, he did not derive it thoroughly. Boulding (1935) derived the IRR for a single investment by equating the initial investment cost to the present value of the expected cash flows of the single investment. Boulding pointed out that the IRR of a single investment could be calculated from the following equation

$$
V_{0}=\frac{E\left[N C F_{1}\right]}{(1+I R R)}+\frac{E\left[N C F_{2}\right]}{(1+I R R)^{2}}+\cdots+\frac{E\left[N C F_{n}\right]}{(1+I R R)^{n}},
$$

where $\mathrm{V}_{0}$ is the initial investment or the current value of the enterprise, $\mathrm{E}\left[\mathrm{NCF}_{\mathrm{i}}\right]$ is period i's expected net cash flow (positive or negative) for $\mathrm{i}=1,2, \ldots, n$, where $n$ is the total number of periods. Boulding argued that any rational investor should choose the project that maximizes his or her IRR. Boulding recognized that the solution of the previous equation is not mathematically simple and thought that a single solution could be found. He did not regard the existence of multiple internal rates of return as problematic. (Note 14)

Keynes (1936) gave the, now familiar and widely known, definition of IRR as the rate of return sets the current asset price equal to the present value of all its future returns. Keyens referred to this definition of IRR as the marginal efficiency of capital. However he mistakenly argued that this IRR definition is the same as Fisher's (1907 and 1930) rate of return on cost.

Samuleson (1937) discussed the contributions made by Keynes (1936) and Boulding (1935) and noted that Boulding's internal rate of return and Keynes' marginal efficiency of capital are equivalent. Samuelson, however, rejected Boulding's view of maximizing IRR. Samuelson pointed out the possibility of no rate of return or of multiple rates, which is considered a major drawback of the IRR criterion.

Interest in DCF methods started to become more significant in the 1950s and became widespread in the 1960s. Parker (1968) reviewed the history of the DCF methods and their use in the 1950s and the 1960s. Nowadays, DCF methods are extensively used in financial valuations as well as a wide variety of applications in finance, business, and economic.

Asset valuation is a method of computing how much an asset is worth today, or in other words, how much investors are willing to pay for a particular asset today. This requires discounting the expected future risky cash flows generated by 
the asset over its future lifetime. Notice that the two key elements of asset valuation are the lifetime of the asset and the anticipated risk in its expected cash flows. This is not surprising since time and risk are the two key ingredients of making any financial decision. In the absence of risk, either in the cash flows or the discount rate, the present value, $V_{0}$, of any asset today is the sum of all its certain future cash flows discounted at the risk-free discount rate; that is,

$$
V_{0}=\frac{C F_{1}}{\left(1+r f_{1}\right)}+\frac{C F_{2}}{\left(1+r f_{2}\right)^{2}}+\cdots+\frac{C F_{n}}{\left(1+r f_{n}\right)^{n}},
$$

Where $C F_{t}$ is the asset's certain cash flow in period $t$, for $t=1,2, \ldots, n, r f_{t}$ is the risk-free rate of return in period $t$, and $n$ is the lifetime of the asset.

This way of asset valuation with certainty is straightforward; just add the future cash flows after discounting them by the period's risk-free rate of return. The valuation problem is more complicated when the future cash flows are subject to random events, i.e., the debt issuer's ability to pay the interest payment in case of bonds, the equity issuer's ability to pay dividends in case of stocks, and the project's ability to generate revenue in case of commercial projects. Thus, solvency, financial strength, and commercial success are considered random events that affect the future cash flows in case of bonds, stocks, and commercial projects respectively. Since these random events are in play, their associated outcomes, i.e., their associated cash flows, are considered random variables with probabilistic realizations. Hence, their expected values are what should be considered in their valuations. If we let $\widetilde{C F}_{t}$ denote the random variable representing the cash flow of a given asset at time $t$ and everything else is the same, then the value of this asset today must follow the following net present value formula.

$$
V_{0}=\sum_{t=1}^{n} \frac{E\left[\widetilde{C F}_{t}\right]}{\left(1+r f_{t}\right)^{t}} .
$$

The formula in (10) is the reference formula for any DCF model. Since randomness implies uncertainty, the only thing remaining is to incorporate such uncertainty, or risk, in the previous formula. Incorporating uncertainty in equation (10) produced many variations of the previous basic DCF formula. One approach augments the risk-free rate by a premium, which takes into account the risk associated with the future uncertainty of the expected cash flows. This risk premium varies from one asset to another. The adjustment of the discount rate in this way produces the following variation of the basic DCF formula:

$$
V_{0}=\sum_{t=1}^{n} \frac{E\left[\widetilde{C F}_{t}\right]}{\left(1+r f_{t}^{*}\right)^{t}}
$$

where $r f_{t}^{*}=r f_{t}+\pi$ is the risk-adjusted discount rate at time $t$. An alternative approach of incorporating uncertainty in the basic DCF formula is to keep the risk-free rate as the discount rate but to decrease period $t$ 's cash flow by a factor $\gamma_{t}$ that represents some risk or insurance premium. This factor takes into account the riskiness of the future cash flow. The adjustment of the cash flows in this way produces the following variation of the basic DCF formula:

$$
\mathrm{V}_{0}=\sum_{\mathrm{t}=1}^{\mathrm{n}} \frac{\mathrm{E}\left[\widetilde{\mathrm{CF}}_{\mathrm{t}}^{*}\right]}{\left(1+\mathrm{rf}_{\mathrm{t}}\right)^{\mathrm{t}^{\prime}}}
$$

where $E\left[\widetilde{C F}_{t}^{*}\right]=E\left[\widetilde{C F}_{t}\right]-\gamma_{t}$ is the risk-adjusted cash flow at time $t$. A third approach in the same spirit of the second is to also keep the risk-free rate as the discount rate but distort the probability distribution of future cash flows to incorporate risk or uncertainty, and then take expectations of the modified cash flows. The notion of uncertainty can also be captured by projecting the cash flows of the asset over different states of nature and then finding a price of the asset today conditional on the realized state in the future.

Among the previous four approaches, the first two are the most frequently used among practitioners in the industry. The third and fourth approaches are more methodological and technical in nature and are based on certain restrictive assumption, which makes their implementation difficult in practice. But, regardless whether the approach is easy or difficult to implement, it should be noted that the transformation of the basic DCF formula that resulted in the previous variations is guided by financial theories. The first two variations are implemented using financial theories on modeling risk-reward relations and computing risk premia such as CAPM and APT. The third variation is based on the martingale approach in finance. The fourth variation is the result of a methodological theory of financial equilibrium known as the state preference theory or Arrow-Debreu's General Equilibrium Theory, after Arrow (1951) and Debreu (1959)'s inventions of state-contingent securities, which are primitive securities that pay one consumption unit if a particular future state occurs and zero otherwise. These state-contingent claims allow the forward trading in a model of market economy.

In practice, as discussed above, the first two variations are mostly used. Moreover, the relevant DCF analysis for the PMP uses variations of the DCF formula to find the fundamental value of an enterprise. The valuation method can be 
executed in two ways: either to value the entire enterprise or to focus only on valuing the investors' stake in the firm. The former way is known as firm valuation whereas the latter is known as equity valuation. We will focus on the latter since it is more relevant to the PMP.

In equity valuation, the focus is on the business equity. Equity valuation, like any other valuation, depends on two inputs: (1) the definition of the equity holders' expected cash flows and (2) the appropriate rate of return, i.e., the discount rate that reflects the riskiness of these cash flows. The first and most straightforward definition of expected equity cash flows is expected dividends. Broader definitions of expected equity cash flows have been also suggested in the literature, e.g., expected equity cash flows that include buybacks in addition to dividends. The definition of expected cash flows varies according to the assumptions made regarding their formation. As for the appropriate rate of return, which is the second input in equity valuation, it is taken to be the required rate of return on equity. The measure of risk differs according to the financial model used in its computation, e.g., the market beta in the CAPM. This, in turn, implies that the required rate of return is not unique for it varies according to the definition of risk.

From the previous discussion, one can conclude that there is not a unique equity valuation model. Different expected cash flows definitions and assumptions and different ways of measuring risks and required rates of return give rise to variants of the equity valuation model. Each variant has its advantages and disadvantages. The first and oldest equity valuation model defines expected equity cash flows as expected dividends. Historically, the link between equity values to expected dividends could be traced back to the work of John Burr Williams (1938) on the theory of investment value, where he suggested that the value of a stock is the present value of all its future dividends Thus, the simplest and the oldest equity valuation model, which is also known as the dividend discount model, can be expressed in the following basic stock valuation formula:

$$
P_{0}=\frac{D_{1}}{\left(1+k_{S}\right)}+\frac{D_{2}}{\left(1+k_{S}\right)^{2}}+\frac{D_{3}}{\left(1+k_{S}\right)^{3}}+\cdots
$$

where $P_{0}$ is the present value of the stock, $D_{t}$ is the expected dividends in period $t$, and $k_{s}$ is the required rate of return or the cost of equity. Notice that the previous formula is perpetuity, i.e., it continues indefinitely, because publicly traded firms can, technically, last forever, and therefore, their dividends are expected to last forever too.

As mentioned earlier, different assumptions regarding the firm's future growth and different ways of measuring the cost of equity gave rise to variants of this basic formula. The first and basic variant is the constant dividend growth model, which assumes that dividends grow at an expected constant growth rate $g$. Following the constant growth assumption, it can easily be shown that the basic stock valuation formula in (13) can be expressed as

$$
P_{0}=\frac{D_{0}(1+g)}{\left(k_{s}+g\right)}
$$

where $D_{0}$ is the last dividend paid in period 0 and $D_{0}(1+g)$ is the dividend expected to be paid in period 1 . Equation (14) states that the value of a stock is the expected dividends next period divided by the cost of equity minus the expected growth rate in perpetuity.

The origins of the constant growth model can be traced back to Durand (1957), who was the first to link the appraisal of constant growth stocks to the Petersburg Paradox; a problem in valuation presented by Daniel Bernoulli in the eighteenth century. Although Durand (1957) was the first to mention the constant growth valuation, it was Myron Gordon (1962) who made the model popular. Nowadays, the constant growth model, which is sometimes referred to as Gordon model, is a standard equity valuation model in any corporate finance textbook. (Note 15)

Aside from the simplicity of the constant growth model, it suffers from the drawback of being limited to firms growing at a constant rate forever. In practice, this situation is highly unlikely. Moreover, as pointed out by Damodaran (2006), practitioners should use the constant growth model with caution. In particular, Damodaran noted that the growth rate of a constantly growing firm should not exceed the economy's GDP growth. Also, if a steady state is assumed, the firm's other measures of performance, such as earnings, should grow at the same growth rate of dividends. (Note 16) In practice, the assumption of constant growth of dividends could be entertained for Blue Chip corporations. However, suggested growth rates should be around 4 to 5 percent or, at most, $6.5 \%$. This is true because the reasonable growth rate of any steady economy is around $4 \%$.

The previous concerns about the constant growth model led practitioners, more so than academicians, to come up with more realistic versions of the constant growth model. This resulted in variable growth models or multistage dividend discount models. See Damodaran (2006) and the references therein for a thorough review.

\subsubsection{Technical Analysis}

Technical analysis is the second type of analysis that is performed by many practitioners during the security selection 
process. Unlike fundamental analysis, which aims to find the true fundamental value of an asset, technical analysis aims to predict its future price movements based only on relevant market data such as price action, trading volume, and open interest.

In one form or another, technical analysis is certainly as old as markets themselves. For example, as stated by Kirkpatrick and Dahlquist (2011), charts were used as early as mid-1600 in the rice futures market in Japan; the birthplace of candlestick charts. Nevertheless, the widespread adoption of technical analysis in the modern markets came out from the Dow Theory; a set of principles concerning market behavior developed by Charles H. Dow in late 19th and early 20th centuries. Charles Dow is also credited with the creation of the Dow Jones Industrial Average (DJIA) in 1896. Since the early days of modern technical analysis, practitioners have been extensively using charts to depict and analyze price movements. For that reason, practitioners using this type of analysis in the finance industry are sometimes referred to as "chartists." Chartists believe that some trends and patterns tend to repeat themselves and they carefully monitor the movement of security prices looking for the early signs of these trends and patterns. They also believe that these patterns reveal information about other market participants that could be useful for predicting how the market as a whole will behave. Due to the, often subjective, nature of observable patterns, which to a large extent depend on how the observer sees them, the validity of fundamental analysis is often questioned by the academic community. In fact, the premise of technical analysis directly contradicts the EMH, which posits that if the possibility of markets efficiency is entertained, then prices should fully reflect all available information, and thus, it should not be possible to use currently available information, e.g., current prices, to gain additional insight about future prices. (Note 17)

Technical analysts rely on a number of various indicators, oscillators, and patterns as means to cut through noise and spot trends in markets data. Most straightforward and common indicators include simple and exponential moving averages, calculated for different periods. Oscillators are a class of indicators that transform market data into a time series that oscillates around or fluctuates between specific values. Some of the most commonly used oscillators include, but not limited to, moving average convergence/divergence, relative strength index, and on balance volume. Patterns include support, resistance, head-and-shoulders, broadening tops, and many others. There are hundreds if not thousands of possible indicators, oscillators and patterns that can be used for technical analysis in practice; an abundance that causes technical analysis to be perceived as less rigorous, and thus, less reliable as opposed to fundamental analysis. It is, perhaps, due to this reason that the literature on technical analysis is scarce. However, a notable comprehensive review of the empirical literature on technical analysis is found in the work of Park and Irwin (2007). In early studies between 1960 and 1987, the authors found strong evidence in the reviewed literature that technical analysis was profitable in foreign exchange markets as well as futures markets, but not in stock markets. However, they identified a number of serious issues, such as data snooping, lack of out-of-sample verification and others that many of the early studies were potentially subject to. On the other hand, in their review of modern studies between 1988 and 2004, there was no consensus; $26 \%$ of the modern studies reviewed showed that technical analysis is not profitable, $11 \%$ reported mixed results, and around $63 \%$ showed evidence that some technical strategies generated profits in a variety of markets. For example, in one particular study by Lo et al (2000), the authors attempted to apply a systematic and automated approach to technical pattern recognition. They tested the effectiveness of several patterns like head-and-shoulders on a number of large US stocks between 1962 and 1999 and were able to conclude that several indicators did provide incremental information that may be useful in the search for profit opportunities. While modern studies were more comprehensive and in general improved significantly on the methodology employed in the early studies by accounting for factors like risk and transaction costs, Park and Irwin concluded that more rigorous research would still be needed to improve our understanding of technical trading strategies. Despite all the efforts, there is still no decisive verdict on the viability of technical analysis versus fundamental analysis and many practitioners tend to use some combination of the two in their security selection process.

\section{Portfolio Evaluation}

Performance evaluation includes measuring performance, comparing the performance to expectations, and then taking corrective actions if necessary. Timely and accurate measuring of performance is critical for asset management. The first set of performance evaluation guidelines appeared in 1987. The guidelines eventually evolved into the Global Performance Investment Standards (GIPS), which is maintained and promoted by the CFA Institute. The objective of the GIPS is to create a unified global standard that allows investors to have confidence in the reported numbers and enables straightforward comparison between performances reported by different asset managers.

When evaluating historical performance of a portfolio, a number of ex-post performance measures can be computed from realized historical returns, such as expected return, volatility, Sharpe ratio, and Jensen's alpha. Performance measures are usually calculated for a number of specified time periods, e.g., 1, 3, or 6 months, and 1, 2, 3, 5 years. Return, volatility and most other measures are almost always annualized in practice to simplify comparison across 
periods.

After performance of investment managers is measured, it is frequently compared to size, book-to-market, or momentum benchmarks. The performance is then broken down by different exposures or factors that drove the return on the portfolio. This process is known as "performance attribution." Attribution analysis allows portfolio managers to identify which investments had the best performance during a particular period and how they contributed to the overall rate of return on the portfolio. Attribution analysis is also very helpful for communicating with the investors and explaining the effect of various allocation decisions. This, in turn, increases the transparency of the management process.

The issue of measuring performance, especially mutual fund performance, has attracted the attention of researchers since the early papers of Sharpe (1966), and Jensen (1968), which argue against persistence in performance of mutual funds, i.e., mutual funds do not systematically outperform their benchmarks. Numerous studies investigating the many factors affecting portfolio performance appeared in the finance literature. Due to space limitation and since investigating portfolio performance is a topic by itself; we will only mention a few significant studies on the topic. Hendricks, Patel, and Zeckhauser (1993) find evidence of persistence in mutual fund performance over short-term horizons (one to three years) and attribute that to the skills of fund managers, for which they reserved the term "hot hands." Goetzmann and Ibboston (1994), Brown and Goetzmann (1995), and Grinblatt, Titman, and Wermers (1995) also find evidence supporting the short-term persistence hypothesis and attribute that to common investment strategies. For longer horizons (five to ten years), see the study of Grinblatt and Titman (1992). Malkiel (1995), Grinblatt and Titman (1989, 1993), Carhart (1997), and Wermers (2000) analyzed mutual fund performance but did not consider the role of the manager and the board (governance).

Finally, it is worth mentioning that other topics could also be tied to measuring performance such as the effects of performance incentives on portfolio managers' decisions and the mangers' beliefs regarding certain aspects of markets' behavior. Both topics were surveyed briefly in Sections 1 and 2 respectively.

\section{Conclusion}

The process of asset allocation and security selection, which is at the core of the PMP, is of particular interest to both academicians and practitioners in the finance industry. Over time, the academic community established two schools of thoughts: the efficient markets school and the behavioral finance school. Likewise, practitioners entertained the views of chartists and fundamentalists. Despite the fact that both, academicians and practitioners, were driven by different motives and that they even shared different beliefs among themselves, their work enhanced our understanding of the price formation process in financial markets. The message that should be taken by young practitioners in the industry is that no one school or view is superior to the other and no common portfolio prescription is available. They should strive to forge their own strategies according to their thoughts and beliefs regarding the behavior of capital markets.

\section{Acknowledgements}

The author would like to thank Denis Chichkine for his excellent research assistance. The financial support of the Math Endowment Fund of University of Waterloo is also acknowledged.

\section{References}

Arrow, K. (1951). An Extension of the Basic Theorems of Classical Welfare Economics, in J. Neyman (ed.), Proceedings of the Second Berkeley Symposium of Mathematical Statistics and Probability, Berkeley, CA: University of California Press, 507-32.

Banz, R. W. (1981). The Relationship between return and market value of common stocks, Journal of Financial Economics, 9(1), 3-18. http://dx.doi.org/10.1016/0304-405X (81)90018-0

Basu, S. (1977). Investment performance of common stocks in relation to their price-earnings ratios: a test of the efficient market hypothesis, Journal of Finance, 12(3), 129-56. http://dx.doi.org/10.2307/2326304

Bhandari, L. C. (1988). Debt/Equity ratio and expected common stock returns: empirical evidence, Journal of Finance, 43(2), 507-28. http://dx.doi.org/10.2307/2328473

Beshears, J., \& Milkman, K. L. (2011). Do sell-side stock analysts exhibit escalation of commitment? Journal of Economic Behavior \& Organization, 77(3), 304-317. http://dx.doi.org/10.1016/j.jebo.2010.11.003

Binay, M. (2005). Performance attribution of US institutional investors, Financial Management, 34(2), 127-152. http://dx.doi.org/10.1111/j.1755-053X.2005.tb00102.x

Black, F. (1972). Capital market equilibrium with restricted borrowing, Journal of Business, 54(3), 444-54. http://dx.doi.org/10.1086/295472

Black, F., \& Litterman, R. (1992). Global portfolio optimization, Financial Analysts Journal, 48(5), 28-43. 
http://dx.doi.org/10.2469/faj.v48.n5.28

Boulding, K. E. (1935). The theory of a single investment, Quarterly Journal of Economics, 49(1), 479-494. http://dx.doi.org/10.2307/1883864

Brinson, G. P., Hood, R. L., \& Beebower, G. L. (1986). Determinants of portfolio performance, Financial Analysts Journal, 42(4), 39-48.

Brinson, G. P., Singer, B. D., \& Beebower, G. L. (1991). Determinants of portfolio performance II: an update, Financial Analysts Journal, 47(3), 40-48.

Brown, S., Goetzman, W., \& Park, J. (2001). Careers and survival: competition and risk in the hedge fund CTA industry, Joural of Finance, 56(1), 1869-1886. http://dx.doi.org/10.1111/0022-1082.00392

Brown, S., \& Goetzmann, W. (1995). Performance persistence, Journal of finance, 50(2), 679-698. http://dx.doi.org/10.2307/2329424

Blume, M. (1984). The use of Alphas to improve performance, The Journal of Portfolio Management, 11(1), 86-92. http://dx.doi.org/10.3905/jpm.1984.408977

Bohm-Bawerk, A. V. (1903). Recent Literature on Interest, Macmilla, London.

Campanella, F. (1972). The Measurement of Portfolio Risk Exposure, Lexington, Mass., D.C. Heath and Co.

Campbell, J., \& Cochrane, H. (1999). By force of habit: a consumption-based explanation of aggregate stock market behavior, Journal of Political Economy, 107(2), 205-251. http://dx.doi.org/10.1086/250059

Carhart, M. (1997). On persistence in mutual fund performance, Journal of Finance, 52(1), 57-82. http://dx.doi.org/10.2307/2329556

Carpenter, J. (2000). Does optimal compensation increase managerial risk appetite? Journal of Finance, 55(5), 2311-2331.

Chen, H., De, P., Hu, Y. J., \& Hwang, B. (forthcoming). Wisdom of crowds: The value of stock opinions transmitted through social media, Review of Financial Studies. http://dx.doi.org/10.1093/rfs/hhu001

Constantinides, G. (1982). Intertemporal asset pricing with heterogeneous consumers and without demand aggregation, Journal of Business, 55(2), 253-267. http://dx.doi.org/10.1086/296163

Damodaran, A. (2006). Damodaran on Valuation (Second Edition), John Wiley and Sons, New York.

DeBondt, W. F. M., \& Thaler, R. H. (1985). Does the stock market overreact? Journal of Finance, 40(3), 793-805.

Debreu, G. (1959). Theory of Value: An Axiomatic Analysis of Economic Equilibrium, New York: John Wiley \& Sons.

Durand, D. (1957). Growth stocks and the St. Petersburg paradox, Journal of Finance, 12(1), 348-363.

Epstein, L. G., \& Zin, S. E. (1989). Substitution, risk aversion, and the temporal behavior of consumption and asset returns: A theoretical framework, Econometrica, 57(4), 937-969. http://dx.doi.org/10.2307/1913778

Fama, E. F. (1970). Efficient capital markets: a review of theory and empirical work. Journal of Finance, 25(2), 383417. http://dx.doi.org/10.2307/2325486

Fama, E. F., \& French, K. R. (1988). Permenant and temporary components of stock prices, Journal of Political Economy, 96(21), 246-273. http://dx.doi.org/10.1086/261535

Fisher, I. (1907). The rate of interst, Macmillan, New York.

Fisher, I. (1930). The theory of interest, Macmillan, New York.

Golec. J. (1992). Empirical tests of a principal-agent model of the investor-investment advisor relationship, Journal of Financial and Quantitative Analysis, 27(1), 81-95. http://dx.doi.org/10.2307/2331299

Golec. J. (1993). The effects of incentive compensation contracts on the risk and return performance of commodity trading advisors, Management Science, 39(1), 1396-1406. http://dx.doi.org/10.1287/mnsc.39.11.1396

Golec, J. \& Starks, L. (2004). Performance fee contract change and mutual fund risk, Journal of Financial Economics, 73(1), 93-118. http://dx.doi.org/10.1016/j.jfineco.2002.05.001

Gordon, M. J., \& Shapiro, E. (1956). Capital equipment analysis: the required rate of profit, Management Science, 3(1), 102-110. http://dx.doi.org/10.1287/mnsc.3.1.102

Gordon, J. M. (1962). The Investment, Financing, and Valuation of the Corporation, Homewood, IL: R.D. Irwin.

Gotezmann, W. N., \& Ibboston, R. G. (1994). Do winners repeat? Patterns in mutual fund return behavior, Journal of Portfolio Management, 20(2), 9-17 
Graham, B., \& Dodd, D. (1934). Security Analysis (Edition 4), McGraw-Hill, New York.

Graham, B. (1949). The Intelligent Investor, Collins, New York.

Grant, D. (1977). Portfolio performance and the "cost" of timing decisions, Journal of Finance, 32, 837-46.

Grinblatt, M., \& Titman, S. (1992). The persistence of mutual fund performance, The Journal of Finance, 47(5), 1977-1984. http://dx.doi.org/10.2307/2329005

Grinblatt, M., Titman, S., \& Wermers, R. (1995). Momentum investment strategies, portfolio performance, and herding: a study of mutual fund behavior, American Economic Review, 85(5), 1088-1105.

Grinblatt, M., \& Titman, S. (1989). Mutual fund performance: An analysis of quarterly portfolio holdings, Journal of Business, 62(3), 394-415. http://dx.doi.org/10.1086/296468

Grinblatt, M., \& Titman, S. (1993). Performance measurement without benchmarks: An examination of mutual fund returns, Journal of Business, 66(1), 47-68. http://dx.doi.org/10.1086/296593

Heinkel, R., \& Stoughton, N. (1994). The dynamics of portfolio management contracts, Review of Financial Studies, 7(1), 351-387. http://dx.doi.org/10.1093/rfs/7.2.351

Hendricks, D., Patel J., \& Zeckhauser, R. (1993). Hot hands in mutual funds: Short-run persistence of relative performance, 1974-1988, Journal of Finance, 48(1), 93-130. http://dx.doi.org/10.2307/2328883

Hood, R. L. (2005). Determinants of portfolio performance-20 years later, Financial Analysts Journal, 61(5), 6-8.

Ibboston, R. G. (2010). The importance of asset allocation, Financial Analysts Journal, 66(2), 18-120.

Ibboston, R. G., \& Kaplan, P. D. (2000). Does asset allocation policy explain 40, 90, or 100 percent of performance? Financial Analysts Journal, 56(1), 26-33.

Jegadeesh, N., \& Titman, S. (1993). Returns to buying winners and selling losers: implications for stock market efficiency, Journal of Finance, 48(1), 93-130. http://dx.doi.org/10.2307/2328882

Jensen, M. C. (1968). The performance of mutual funds in the Period 1945-1964. Journal of Finance, 23(2), 389-416. http://dx.doi.org/10.2307/2325404

Keynes, J. M. (1936). The General Theory of Employment, Interest, and Money, New York: Harcourt Brace.

Kirkpatrick, C. D., \& Dahlquist, J. R. (2011). Technical Analysis: The Complete Resource for Financial Market Technicians, Upper Saddle River, NJ.

Lintner, J. (1965). The valuation of risk assets and the selection of risky investments in stock portfolios and capital budgets, Review of Economics and Statitistics, 47(1), 13-37. http://dx.doi.org/10.2307/1924119

Lo, A. W. (2004). The adaptive markets hypothesis: market efficiency from an evolutionary perspective, Journal of Portfolio Management, 30(1), 15-29.

Lo, A. W., \& MacKinlay, A. C. (1988). Stock market prices do not follow random walks: Evidence from a simple specification test, Review of Financial Studies, 1(1), 41-66.

Lo, A. W., \& MacKinlay, A. C. (1990). When are contrarian profits due to stock market overreaction? Review of Financial Studies, 3(2), 175-205.

Lo, A. W., Mamaysky, H., \& Wang, J. (2000). Foundations of techical analysis: computational algorithms, statistical inference, and empirical implementation. The Journal of Finance, 55(4), 1705-1770. http://dx.doi.org/10.1111/0022-1082.00265

Lucas, R. J. (1976). Econometric policy evaluation: A critique, Carnegie-Rochester Conference Series on Public Policy, $1(1), 19-46$.

Malkiel, B. G. (1995). Returns from investing in equity mutual funds, 1971-1991, Journal of Finance, 50(2), $549-572$. http://dx.doi.org/10.2307/2329419

Mankiw, N. G., \& Zeldes, S. P. (1991). The consumption of stockholders and nonstockholders, Journal of Financial Economics, 29(1), 97-112. http://dx.doi.org/10.1016/0304-405X (91)90015-C

Markowitz, H. M. (1959). Portfolio Selection: Efficient Diversification of Investment, Cowels Foundation Monograph, New York: John Wiley \& Son, Inc.

Marshall, A. (1907). Principles of Economics, Macmillan, London.

Mehra, R., \& Prescott, E. C. (1985). The equity premium: A puzzle, Journal of Monetary Economics, 15(2), $145-161$. http://dx.doi.org/10.1016/0304-3932 (85)90061-3 
Merkley, J., \& Levin, C. (2011). The Dodd-Frank Act restrictions on proprietary trading and conflicts of interest: New tools to address evolving threats, Harvard Journal on Legislation, 48(2), 515-558.

Modigliani, F., \& Progue, G. (1975). Alternative investment performance fee arrangements and implications for SEC regulatory policy, Bell Journal of Economics, 6, 127-160.

Nyquist, P. (1995). Failure to engage: the regulation of proprietary trading systems, Yale Law \& Policy Review, 13(2), 281-337.

Park C-H., \& Irwin S. H. (2007). What do we know about the profitability of technical analysis? Journal of Economic Surveys, 21(4), 786-826. http://dx.doi.org/10.1111/j.1467-6419.2007.00519.x

Parker, H. (1968). Discounted cash flow in historical perspective, Journal of Accounting Research, 6(1), 58-71. http://dx.doi.org/10.2307/2490123

Poterba, J., \& Summers, L. (1988). Mean reversion in stock returns: Evidence and implications, Journal of Financial Economics, 22(1), 27-59.

Rosenberg, B., Reid, K., \& Lanstein, R. (1985). Persuasive evidence of market inefficiency, Journal of Portfolio Management, 11(3), 9-17. http://dx.doi.org/10.3905/jpm.1985.409007

Ross, S. A. (1976). The arbitrage theory of capital asset pricing, Journal of Economic Theory, 13(3), 341-360. http://dx.doi.org/10.1016/0022-0531(76)90046-6

Ross, S. (2004). Compensation, incentives, and the duality of risk aversion and riskiness, The Journal of Finance, 59(1), 207-225. http://dx.doi.org/10.1111/j.1540-6261.2004.00631.x

Samuelson, P. (1937). Some aspects of the pure theory of capital, Quarterly Journal of Economics, 51(1), 469-496. http://dx.doi.org/10.2307/1884837

Sharpe, W. F. (1964). Capital asset prices: A theory of market equilibrium under conditions of risk, Journal of Finance, 19(3), 425-442. http://dx.doi.org/10.2307/2977928

Sharpe, W. F. (1966). Mutual fund performance, Journal of Business, 39(1), 119-138. http://dx.doi.org/10.1086/294846

Sharpe, W. F. (1975). Likely gains from market timing, Financial Analysts Journal, 31(2), 60-69. http://dx.doi.org/10.2469/faj.v31.n2.60

Starks, L. (1987). Performance incentive fees: an agency theoretic approach, Journal of Financial and Quantitative Analysis, 22(1), 17-32. http://dx.doi.org/10.2307/2330867

Stattman, D. (1980). Book values and stock returns, The Chicago MBA: A Journal of Selected Papers, 4, 25-45.

Tobin, J. (1958). Liquidity preference as behavior towards risk, Review of Economic Studies, 25(67), 65-86. http://dx.doi.org/10.2307/2296205

Treynor, J. L., \& Mazuy, K. (1966). Can mutual funds outguess the market? Harvard Business Review, 44, 131-136

Vardharaj, R., \& Fabozzi, F. J. (2007). Sector, style, region: explaining stock allocation performance, Financial Analysts Journal, 63(3), 59-70. http://dx.doi.org/10.2469/faj.v63.n3.4691

Wermers, R. (2000). Mutual fund performance: An empirical decomposition into stock-picking talent, style, transactions costs, \& expenses, The Journal of Finance, 55(4), 1655-1695. http://dx.doi.org/10.1111/0022-1082.00263

Wicksell, K. (1954). Value, Capital, and Rent, George Allen \& Unwin LTD., London

Williams, J. B. (1938). The Theory of Investment Value, Harvard University Press.

Xiong, J., Ibboston, R. G., Idzorek, T., \& Chen, P. (2010). The equal importance of asset allocation and active management, Financial Analysts Journal, 66(2), 22-30. http://dx.doi.org/10.2469/faj.v66.n2.7

\section{Notes}

Note 1. For more details on the regulation of proprietary trading systems, see Nyquist (1995) and Merkley and Levin (2011) and the references therein.

Note 2. In the United States, mutual funds are regulated by the Investment Company Act (1940).

Note 3. The report of investigation of failure of the SEC to Uncover Bernard Madoff's Ponzi scheme (Case No. OIG-509) provided by the United States SEC Office of Inspector General can be accessed online through the following link: http://www.sec.gov/spotlight/secpostmadoffreforms/oig-509-exec-summary.pdf.

Note 4. That's why when back tests are shown to clients, a disclaimer is always displayed, e.g., "past performance may 
not be indicative of future results."

Note 5. This indeed true since pension plan sponsors usually select a long-term strategic asset allocation target and stick to it. However, as Ibboston and Kaplan (2000) argued, if plan sponsors were more active, the $R^{2}$ from the previous regressions would have been smaller.

Note 6. For a recent review, see Ibboston (2010).

Note 7. To understand why the efficient frontier is the entire straight line when borrowing and lending are allowed, consider combining the risk-free asset one time with portfolio $\mathrm{L}$ and another time with portfolio $\mathrm{B}$. By constructing portfolio $[\mathrm{rf}+\mathrm{L}]$, the investor is investing a percentage of his or her wealth, $w_{L}$, where $w_{L}<1$, in the market portfolio $\mathrm{M}$ and the remaining wealth $\left(1-w_{L}\right)$ in the risk-free asset. The investor is a lender in this case as shown from point $\mathrm{L}$ on the efficient frontier in Figure 5. On the other hand, an aggressive investor, who wishes to achieve a rate of return above the market, will borrow $\left(w_{B}-1\right)$, where $w_{B}>1$, of the available amount of wealth that he or she has at the risk-free rate and then, invest everything (the original wealth plus the borrowed amount) in the market portfolio M. This leads to the construction of portfolio [rf+ B], where point B is on the extended efficient frontier. Therefore, in short, adding a risk-free borrowing and lending to the Markowitz analysis extends the linear efficient frontier AM all the way up and above $\mathrm{M}$ to accommodate borrowing choices.

Note 8 . The market portfolio is the value-weight market portfolio or risky assets, where the weight of asset $i$ in the market portfolio is the market value of all outstanding unitsof the assets divided by total market value of all risky assets.

Note 9. The market beta coefficient of asset $i$ in the CAPM equation is computed as $\beta_{i M}=\operatorname{cov}\left[r_{i}, r_{M}\right] / \operatorname{var}\left[r_{M}\right]$ and could be interpreted in two ways: It could be seen as the slope of the regression of asset $i$ 's excess rate of return, $\left(E\left[r_{i}\right]-r_{f}\right)$, on the market excess rate of return $\left(E\left[r_{M}\right]-r_{f}\right)$, which is seen as a measure of sensitivity of the asset's rate of return to variations in the market return. Alternatively, it could be interpreted as the covariance risk of asset $i$ in $\mathrm{M}$ measured relative to the average covariance risk of all assets, which is just the variance of the market. In economic terms, the market beta coefficient of asset $i$ is the risk contribution of asset to the market portfolio. In other words, it is proportional to the risk each dollar invested in asset $i$ contributes to the market portfolio.

Note 10. For an excellent recent survey, see Fama and French (2004) and the references therein.

Note 11. For an excellent survey on the theoretical and empirical literature on efficient capital markets models, the interested reader is advised to consult Fama (1970) and the references therein.

Note 12. Actually this statement was Graham's own words. It was recorded in an interview in March 1976 in Graham's home in California. The interviewer, Mr. Hartman L. Butler, sat for an hour with Graham talking, among many things, about his new book. The interview is known as "An Hour with Mr. Graham."

Note 13. I should also mention that there is a fourth approach to valuation, which is the contingent claim valuation approach, where the value of an asset is measured using derivative or option pricing models. This approach, however, is a topic by itself and is beyond the scope of this paper. For more details on the second and third approaches to valuation, the interested reader is advised to consult Damodaran (2006).

Note 14. One of the drawbacks of the conventional IRR method is that it yields multiple rates of return, which could be ambiguous and confusing sometimes.

Note 15. Bernoulli's paper, which was originally written in Latin in St. Petersburg in 1738 and later translated into English in 1954, is considered a breakthrough in the analysis of decisions under uncertainty. Bernoulli presented the paradox and suggested a solution. According to Bernoulli (1954), the rule of mathematical expectations used in valuing risky outcomes, e.g., outcomes of a lottery or gamble, should be discarded. His rationale is that two people facing the same lottery may value it differently because of a difference in their psychology; a thousand dollars gains is more valuable to a poor fellow to a rich one. Although the gain is the same, but the value is different for different people. Thus, the value of an item must not be based on its price, but rather on the utility that it yields.

Note 16. To see why in a steady state, the growth rate of earnings must be the same as the growth rate of dividends, assume otherwise and see the effect on the payout ratio. In particular, if earnings growth exceeds dividends growth, the payout ratio in the long run converges to zero, which is inconsistent with a steady state.

Note 17. Fama (1970) surveyed the theory of the EMH and documented its forms, i.e., the weak and strong forms of $\mathrm{EMH}$, and the literature pertaining to each form. 
Appendix A. Major Types of Institutional Investors

\begin{tabular}{|c|c|}
\hline \multicolumn{2}{|l|}{ 1. Retail and commercial banks } \\
\hline Description of main business activities & Accept deposits and make loans to individuals and businesses \\
\hline Common sources of investment funds & Deposits, debt, and equity \\
\hline Common investment goals & Preservation of capital, protection against inflation, asset stability \\
\hline Examples in Canada & CIBC, TD, BMO, RBC, and Scotia Bank \\
\hline \multicolumn{2}{|l|}{ 2. Investment Banks } \\
\hline Description of main business activities & Research, underwrite, promote, and sell securities to institutional buyers \\
\hline Common sources of investment funds & Client funds, borrowing, and own revenues \\
\hline Common investment goals & Market making, generating gains for clients, proprietary gains \\
\hline Examples in Canada & CIBC World Markets, TD Securities, and BMO Capital Markets \\
\hline \multicolumn{2}{|c|}{ 3. Asset Management and Investment Advisory Companies } \\
\hline Description of main business activities & $\begin{array}{l}\text { Manage various types of funds and provide investment advise to cleints } \\
\text { exchange-traded funds,. }\end{array}$ \\
\hline Common sources of investment funds & Funds from institutional or individual clients \\
\hline Common investment goals & Achieving clients' investment goals \\
\hline Examples in Canada & RBC Asset Management, Investors Group, and TD Asset Management \\
\hline \multicolumn{2}{|l|}{ 4. Defined Benefits Pension Funds } \\
\hline Description of main business activities & Administer and invest retirement funds for regular employees \\
\hline Common sources of investment funds & Pension contributions by employees and plan sponsors (employers) \\
\hline Common investment goals & Meeting retirement obligations and goals \\
\hline Examples in Canada & Canada Pensions Plan Investment Board \\
\hline \multicolumn{2}{|l|}{ 5. Insurance companies } \\
\hline Description of main business activities & Provide insurance products \\
\hline Common sources of investment funds & Insurance premiums \\
\hline Common investment goals & Maintaining sufficient funds for paying out claims \\
\hline Examples in Canada & Manulife Financial, Great-West Life co., and Sun Life Financial \\
\hline \multicolumn{2}{|l|}{ 6. Foundations } \\
\hline Description of main business activities & $\begin{array}{l}\text { Fund a specific cause with regular spending (usually humanitarian, } \\
\text { environmental or political) }\end{array}$ \\
\hline Common sources of investment funds & Donations and contributions \\
\hline Common investment goals & Sufficiently funding the cause \\
\hline Examples in Canada & The Master Card Foundation \\
\hline \multicolumn{2}{|l|}{ 7. Endowments Funds } \\
\hline Description of main business activities & Provide income and long-term stability usually to non-profit institutions \\
\hline Common sources of investment funds & Donations and contributions \\
\hline Common investment goals & $\begin{array}{l}\text { Generating income to supplement budget, providing long-term stability to } \\
\text { parent institution }\end{array}$ \\
\hline Examples in Canada & Math Endowment Fund (MEF), University of Waterloo \\
\hline \multicolumn{2}{|l|}{ 8. Sovereign Wealth Funds } \\
\hline Description of main business activities & $\begin{array}{l}\text { Invest government's savings and provide stabilization for the budget } \\
\text { throughout an economic cycle }\end{array}$ \\
\hline Common sources of investment funds & Commodity export revenues, foreign exchange reserves, tax revenues \\
\hline Common investment goals & Providing fiscal stability and funding budget deficits \\
\hline Examples in Canada & None \\
\hline \multicolumn{2}{|l|}{ 9. Corporations } \\
\hline Description of main business activities & Provision of various goods and services \\
\hline Common sources of investment funds & Revenue, debt, and equity \\
\hline Common investment goals & $\begin{array}{l}\text { Generating value for shareholders, protecting idle funds against inflation, } \\
\text { hedging business risks }\end{array}$ \\
\hline Examples in Canada & Suncor Energy and Canadian National Railway \\
\hline
\end{tabular}

Description: The common major types of institutional investors, their primary activities, their typical sources of investment funds and investment goals, and some prominent examples of these institutional investors in Canada.

\section{(c) EY}

This work is licensed under a Creative Commons Attribution 3.0 License. 